\title{
Onset Neurones in the Anteroventral Cochlear Nucleus Project to the Dorsal Cochlear Nucleus
}

\author{
Robert H. Arnott, Mark N. Wallace, Trevor M. Shackleton, and Alan R. Palmer \\ MRC Institute of Hearing Research, University Park, Nottingham, NG7 2RD, UK
}

Received: 9 September 2003; Accepted: 17 November 2003; Online publication: 4 March 2004

\begin{abstract}
Considerable circumstantial evidence suggests that cells in the ventral cochlear nucleus, that respond predominantly to the onset of pure tone bursts, have a stellate morphology and project, among other places, to the dorsal cochlear nucleus. The characteristics of such cells make them leading candidates for providing the so-called "wideband inhibitory input" which is an essential part of the processing machinery of the dorsal cochlear nucleus. Here we use juxtacellular labeling with biocytin to demonstrate directly that large stellate cells, with onset responses, terminate profusely in the dorsal cochlear nucleus. They also provide widespread local innervation of the anteroventral cochlear nucleus and a small innervation of the posteroventral cochlear nucleus. In addition, some onset cells project to the contralateral dorsal cochlear nucleus.
\end{abstract}

Keywords: stellate cells, anteroventral cochlear nucleus, dorsal cochlear nucleus, wideband inhibitor, onset responses

\section{INTRODUCTION}

The cochlear nucleus consists of three functionally and anatomically separate divisions: the anteroventral cochlear nucleus (AVCN), the posteroventral cochl-

Correspondence to: Alan R. Palmer - MRC Institute of Hearing Research - University Park - Nottingham, NG7 2RD, UK - Telephone: +44 115922 3431; Fax: + 44115951 8503; email: alan@ ihr.mrc.ac.uk ear nucleus (PVCN), and the dorsal cochlear nucleus (DCN) (Rose et al. 1959). Responses of auditory nerve fibers to simple tone burst stimuli are rather homogenous (Kiang et al. 1965), whereas cells in the cochlear nucleus provide diverse responses to simple tones (e.g., Young 1984). In the ventral division, many morphological cell types have been distinguished. Some have very distinctive morphologies, such as the granular, Golgi, and octopus cells and the globular and spherical bushy cells. However, others form part of a diverse class of stellate or multipolar cells which vary in size, from small to giant, with either smooth dendrites or varying densities of spines (Osen 1969; Brawer et al. 1974). Bushy cells provide more-or-less faithful transmission of auditory nerve firing patterns (Pfeiffer 1966) and project this information into pathways for comparison of the activity from the two ears to extract cues for localizing sounds. Stellate cells have more diverse physiological properties, producing a variety of onset or choppingtype responses (Young et al. 1988; Blackburn and Sachs 1989; Smith and Rhode 1989; Winter and Palmer 1990).

Two main classes of stellate cells in VCN have been described based on a number of different criteria. Some of the criteria are purely structural while others are functional, but there seems to be a good correspondence between them. The first class has variously been termed type I (sparse synapses formed on the soma) (Cant 1981), small planar or marginal cells (Doucet and Ryugo 1997), type T (axon projecting into the trapezoid body) (Oertel et al. 1990), glycine negative (Alibardi 1998, 2001), and cells with chopping responses (Smith and Rhode 1989). The second class has been termed type II (dense covering of synapses on the soma), large radiate cells, type D (dorsal projecting axons), glycine positive, and cells 
with onset responses (by the same authors). Chopping describes regular, sustained discharge characteristics determined by membrane biophysics rather than being related to the stimulus waveform. Onset cells, stimulated close to threshold, produce only a few spikes locked to the onset of the stimulus and have little if any sustained activity. Chopping responses are typical of small, smooth stellate cells and the difference between these cells and the large stellate cells with onset properties has been described elsewhere (e.g., Palmer et al. 2003). Three types of onset cells have been characterized in the guinea pig cochlear nucleus: these are the On-C (57\% of the population), On-L (34\%), and On-I (9\%) (Winter and Palmer 1995). The On-C cells have more than one peak at the onset, the other two have a single peak at the onset, but, while the On-L and On-C cells can have sustained rates of $>10 \mathrm{spikes} / \mathrm{s}$, the On-I have sustained rates of $<10$ spikes/s.

Networks of cells in the dorsal cochlear nucleus have been implicated in the processing of localization cues in the spectral domain generated by interactions of sound waves in the pinna and concha (Young and Davis 2002). For their operation, these networks require input from a cell termed a "wideband inhibitor," as illustrated in Figure 1. The physiological response profile of onset cells in the ventral cochlear nucleus suggests that either or both of the On-C and On-L types might be candidates for this network element (Nelken and Young 1994; Winter and Palmer 1995; and see, e.g., Rhode 1999; Davis and Young 2000). In contrast, the On-I types have a very narrow dynamic range and are unlikely to be involved in this pathway. Here we used juxtacellular labeling to demonstrate directly the projection of onset-responding stellate cells into the dorsal division of the cochlear nucleus.

\section{MATERIALS AND METHODS}

\section{Animal preparation}

Experiments were carried out using male and female pigmented guinea pigs ranging from 350 to $600 \mathrm{~g}$ in accordance with the United Kingdom Animals (Scientific Procedures) Act 1986. Animals were anesthetized with urethane $(1.3 \mathrm{~g} / \mathrm{kg} \mathrm{IP}$, in $20 \%$ solution in $0.9 \%$ saline) and Hypnorm (0.2 ml IM, comprising fentanyl citrate $0.315 \mathrm{mg} / \mathrm{ml}$ and fluanisone $10 \mathrm{mg} /$ $\mathrm{ml})$. Atropine sulfate $(0.06 \mathrm{mg} / \mathrm{kg} \mathrm{SC})$ was administered at the start of the experiment. Anesthesia was supplemented, on indication, with further doses of Hypnorm (0.2 ml IM).

A tracheotomy was performed, followed by bilateral exposure of the ear canal. The animal was mounted in a stereotaxic frame in which the ear bars were re- placed with plastic speculae to allow visualization of the tympanic membrane and delivery of sound stimuli. A craniotomy was made which extended from approximately $2 \mathrm{~mm}$ behind the nuccal ridge to lambda and from approximately $2 \mathrm{~mm}$ to the right of the midline to approximately $6 \mathrm{~mm}$ to the left. The dura was reflected and the surface of the brain covered by a solution of $1.5 \%$ agar in $0.9 \%$ saline to prevent desiccation and to aid stability. The angle of the head was adjusted such that the surface of the skull in the rostrocaudal axis was displaced downward by $20^{\circ}$ from horizontal toward the front of the animal. The animal's temperature was maintained at $37^{\circ} \mathrm{C}$ throughout the experiment by means of a thermostatically controlled heating blanket. Respiratory rate and heart rate were monitored routinely.

\section{Stimulation recording, and juxtacellular labeling}

Experiments were carried out in a sound-attenuated booth. Stimuli were delivered through a sealed acoustic system comprising custom-modified Radio Shack 40-1377 tweeters (M. Ravicz, Eaton Peabody Laboratory, Boston, MA) coupled to damped $4 \mathrm{~mm}$ diameter probe tubes which fitted into the speculum. In every experiment, a probe tube microphone was used to calibrate the sound system, close to the tympanic membrane, using a Brüel and Kjaer 4134 microphone fitted with a calibrated $1 \mathrm{~mm}$ probe tube. The sound system response on each side was flat to within $\pm 10 \mathrm{~dB}$ from 100 to $35,000 \mathrm{~Hz}$.

Stimuli consisted of $50 \mathrm{~ms}$ bursts of wideband noise or pure tone $(0.1-40 \mathrm{kHz})$ which were presented to the left ear (ipsilateral to the recording site) every $200 \mathrm{~ms}$. All stimuli were generated by an array processor (Tucker-Davis Technologies, Alachua, FL, Model AP2) and output was at rates of at least $100 \mathrm{kHz}$. The maximum output level was set to approximately $100 \mathrm{~dB}$ SPL.

Single cell activity was initially recorded via tungsten-in-glass microelectrodes (Bullock et al. 1988) which were positioned using a piezoelectric motor (Inchworm IW-711-00, Burleigh Instruments, New York). The microelectrodes were angled at $45^{\circ}$ and were placed stereotaxically. Once an area of onset responding cells had been identified, the tungsten electrode was withdrawn and replaced with an aluminosilicate glass capillary ( $1 \mathrm{~mm}$ outer diameter, Clarke Electromedical, Pangbourne, UK), pulled and broken back to give a tip impedance of 15-30 $\mathrm{M} \Omega$, and filled with $1.5 \%$ biocytin (Sigma, St. Louis, MO) in $0.5 \mathrm{M}$ sodium chloride. The glass electrodes were not used for the initial mapping because their tips were easily damaged and their wider shafts tended to produce more tissue damage than the slimmer tungsten electrodes. 


\section{Output to the inferior colliculus}
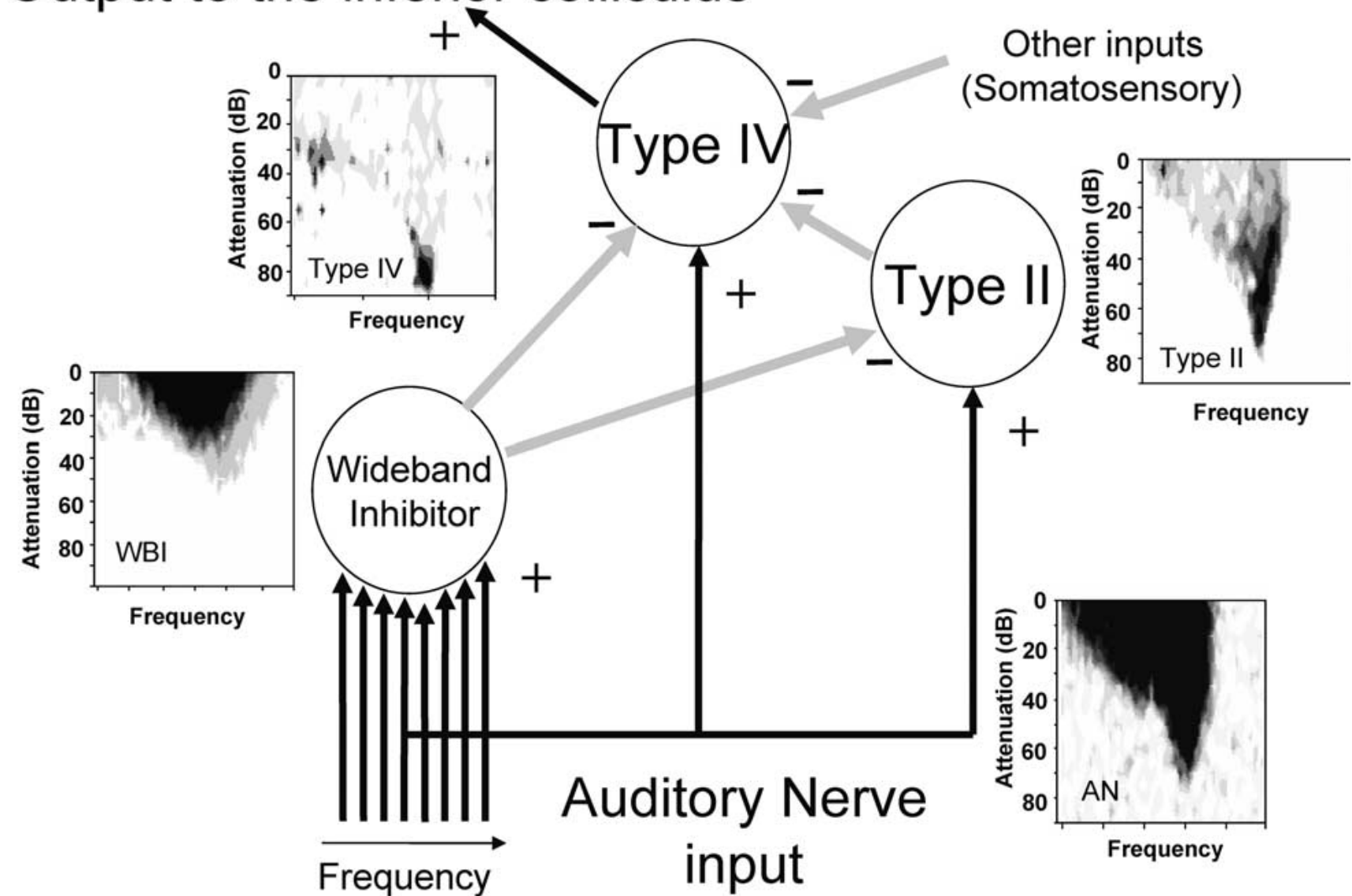

Frequency

FIG. 1. The proposed network of cells in the cochlear nucleus that result in type IV principal cells being highly responsive to the frequency position of sharp spectral notches (Young and Davis 2002). Black (+) arrows indicate excitatory connections while gray $(-)$ arrows show inhibitory connections. Typical frequency response areas

When a single cell with onset characteristics (Winter and Palmer 1995) was isolated, the cell's characteristic frequency and minimum threshold for response were determined. The cell was characterized physiologically by determining its frequency response area, by constructing rate-level functions to best frequency tone and to noise stimuli, and by constructing poststimulus time histograms of responses evoked by best frequency tone and noise stimuli which were delivered at 20 and $50 \mathrm{~dB}$ above the characteristic frequency response threshold.

Following physiological characterization, the cell was labeled with biocytin according to the juxtacellular method of Pinault (1996). Briefly, biocytin was ejected from the recording pipette under physiological control using +3 to +11 nA square wave current pulses, of $200 \mathrm{~ms}$ duration (50\% duty cycle), which were injected using the current injection circuit of the microelectrode amplifier. Adequate current injection, sufficiently close to the cell, caused action potentials to be evoked robustly during the depolar-

for each cell type are shown; these are from real recordings and are for illustration of the shape only. Note that the full extent of the wideband inhibitor response area is rarely revealed by single-tone stimulation.

izing epochs. The current strength was titrated carefully to ensure that the cell remained firing throughout the labeling but was not damaged by overdriving; strong labeling occurred when current injection-associated firing was maintained for 4$15 \mathrm{~min}$. We gained the impression that the duration of current injection, during which action potentials were elicited (with currents in the range +5 to +10 $\mathrm{nA}$ ), was the most significant factor governing the distance through which a neurone might be traced subsequently.

\section{Histology and anatomical reconstruction}

Following up to $9 \mathrm{~h}$ of survival (during which time we undertook recordings from the contralateral inferior colliculus for a different study), the animal was given an overdose of sodium pentobarbitone and perfused transcardially with $500 \mathrm{ml}$ of phosphate buffer (PB) $\mathrm{pH} 7.4$ containing $4 \%$ paraformaldehyde and $0.5 \%$ 
glutaraldehyde. The brain was removed and stored in the same fixative overnight at $4^{\circ} \mathrm{C}$.

The following day, the brain was embedded in a mixture of gelatin and egg albumin and serial $50 \mu \mathrm{m}$ coronal sections were cut using a vibratome. The freely floating sections were washed twice in $\mathrm{PB}$ and incubated overnight at $4^{\circ} \mathrm{C}$ in $\mathrm{PB}$ containing $0.3 \%$ Triton X-100 and avidin-biotin peroxidase complex (ABC Elite, Vector Laboratories, Burlingame, CA). The sections were washed twice in PB before being incubated for $10 \mathrm{~min}$ with $0.05 \%$ diaminobenzidine (DAB), $0.005 \%$ hydrogen peroxide, $0.0015 \%$ nickel ammonium sulfate, and $0.0015 \%$ cobalt chloride in PB. The sections were washed twice and mounted on coated slides.

Three-dimensional reconstructions were undertaken using computer software (Neurolucida, Microbrightfield, Colchester, VT) connected to a microscope (Axioskop2, Carl Zeiss). DAB-stained material was traced using a $40 \times$ objective lens (NA 0.95 ) within the traced boundaries of the $\mathrm{CN}$ and the brain stem in each section. The perfusion and sectioning did not produce any shrinkage that we could measure, but the sections did become thinner after they were mounted and had dried onto the slides. We compensated for this by resetting the $Z$ value of the reconstruction after drawing each section so that the coordinates for each new section started exactly $20 \mu \mathrm{m}$ further on than the start of the previous section. When making the reconstructions, we introduced a shrinkage compensation factor of $2.5 \times$ to compensate for the fact that the sections were cut at $50 \mu \mathrm{m}$.

\section{RESULTS}

Twenty neurones in AVCN were characterized physiologically, labeled, and recovered histologically. Five of these neurones corresponded to the On-C type and two to the On-L type (Smith and Rhode 1986; Winter and Palmer 1995). This report describes only these onset cells, the others are described in Palmer et al. (2003). In common with the earlier studies, our onset neurones frequently exhibited higher response thresholds than those associated with other CN neurones (e.g., chop-S neurones). Considerably lower thresholds were frequently measured in non-onset neurones with similar best frequencies (BFs), which were encountered within a few hundred microns of our onset neurones. This fact suggested that the higher thresholds of the onset cells did not reflect cochlear pathology. Our onset cells had minimum thresholds that varied from 23 to $70 \mathrm{~dB}$ SPL and best frequencies varied from $0.98 \mathrm{kHz}$ to $11.1 \mathrm{kHz}$.

\section{On-C neurones}

Physiological responses. Five cells, labeled in the AVCN, were of the type defined as On-C by Winter and Palmer (1995). Response profiles from three fully reconstructed cells are shown in Figures 2-4. The poststimulus time histograms (PSTHs) of On-C neurones for responses to $>20 \mathrm{~dB}$ suprathreshold $\mathrm{BF}$ tone bursts exhibited more than one initial peak (arrows in Fig. 2D,E). On-C neurones exhibited monotonic, nonsaturating rate-level functions to both $\mathrm{BF}$ tones and noise (Figs. 2B, $4 \mathrm{~B}$ and $2 \mathrm{C}, 4 \mathrm{C}$, respectively). Their response areas were of type I/III after Young (1984) which consisted only of an excitatory area since the spontaneous rate was too low to show any single tone inhibition. The five cells of this type had BFs of $0.98,1.2,5.9,6.3$, and $8.2 \mathrm{kHz}$.

Anatomical arrangement. All five of our On-C neurones possessed a similar anatomy. This assessment was confirmed by fully reconstructing four of the cells using Neurolucida ${ }^{\mathrm{TM}}$ (Neurolucida, Microbrightfield, Colchester, VT). Three of the cells whose physiological responses are shown in Figures 2-4 are shown in Figures 5-7. The On-C cells had large, multipolar, ovoid somata (diameter $\sim 27 \mu \mathrm{m}$ ) with aspinous dendrites (Fig. 8). Four of the On-C cells had 4 primary dendrites, while one had 7 . The total dendritic length (sum of all dendrites) of the 4 reconstructed cells ranged from 6222 to $7351 \mu \mathrm{m}$ (mean-6665 $\mu \mathrm{m}$ ). The dendrites extended widely in all directions. The restricted width of the cochlear nucleus meant that, in the mediolateral plane, the dendrites often spanned almost its entire extent. The majority of the dendrites remained largely unbranched and tapered before giving rise to a few fine, distal branches.

The tonotopic gradient within AVCN starts with high frequencies at the dorsocaudal edge and ends with low frequencies at the ventroanterior edge; it has approximately the same orientation as our electrode tracks. The position of labeled processes, in relation to this gradient, was assessed by reconstructing some of the surrounding electrode tracks where BFs had been recorded (Fig. 9A,B). This procedure was possible for only two of the On-C cells because it required several visible tracks which could be linked with tonotopic information. In two cases, the electrode track involving the injection could be visualized directly (because of the blood within it); the other tracks were related to it by their stereotaxic coordinates. A track was identified as the injection track when it passed within $100 \mu \mathrm{m}$ of the soma. The dendrites (in green) appeared to extend over distances that would have received inputs centered less than an octave away from their BF; they certainly did not span the whole tonotopic range. 

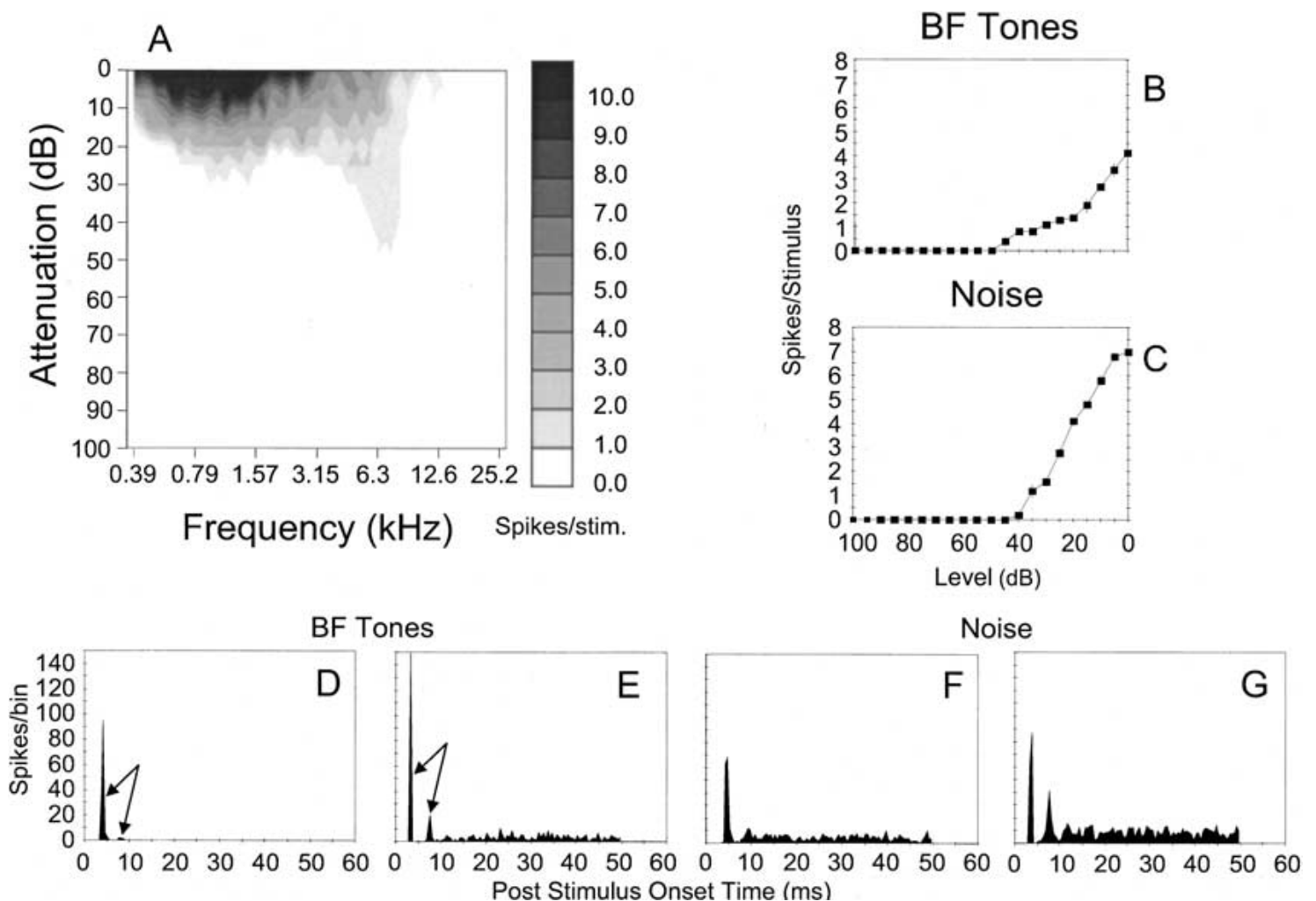

FIG. 2. Physiological characteristics of unit $282(\mathrm{BF}-6.3 \mathrm{kHz})$ identified as an On-C type. A Frequency response area showing the distribution of spikes as a function of stimulus frequency (abscissa) and level (ordinate). B, C Discharge rate versus level function showing mean $( \pm$ SEM) number of discharges per stimulus. The ordinate shows attenuation in decibels below maximum output (ap- proximately $100 \mathrm{~dB}$ SPL) for BF tones $(\mathbf{B})$ and broadband noise $(\mathbf{C})$. D, E PSTHs compiled from 150 presentations of $50 \mathrm{~ms}$ BF tone bursts, which were delivered at $20 \mathrm{~dB}$ and $50 \mathrm{~dB}$ suprathreshold. Binwidth-1 ms. F, G Similar PSTHs compiled from responses to bursts of broad band noise delivered with $20 \mathrm{~dB}$ and $0 \mathrm{~dB}$ of stimulus attenuation (cf. C).

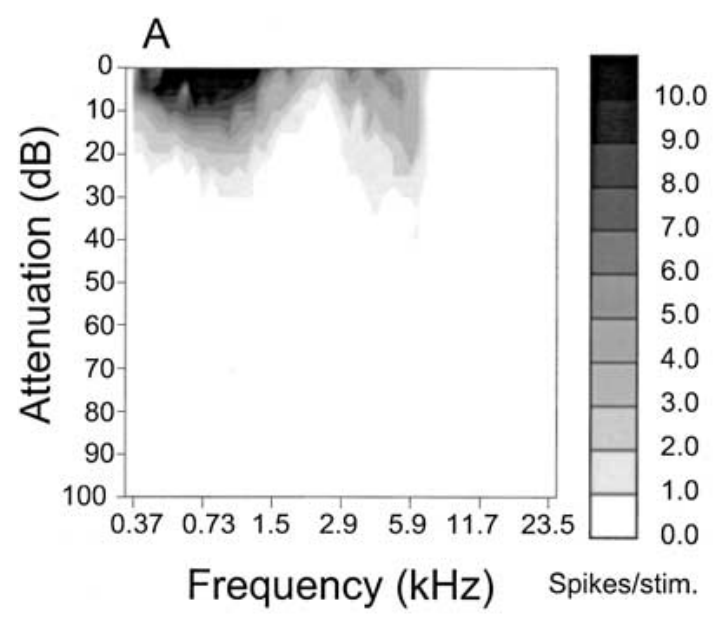

Axon terminations in AVCN. The On-C cells possessed single axons that arose either from an axon hillock, which was contiguous with the soma, or from the proximal part of a large dendrite within approximately $15 \mu \mathrm{m}$ of the soma. Figure 5 shows the pattern of projection, within VCN, of the neurone whose

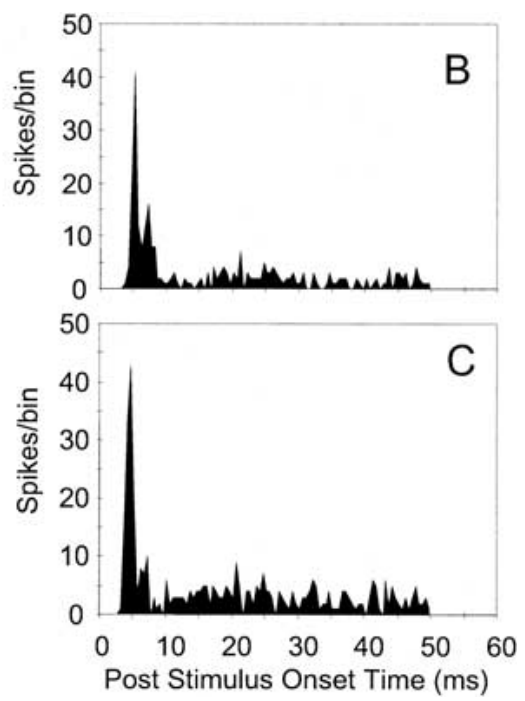

FIG. 3. Physiological characteristics of unit $212(\mathrm{BF}-5.9 \mathrm{kHz})$ identified as an On-C type. A Frequency response area. B, C PSTHs compiled from responses to 150 presentations of $50 \mathrm{~ms}$ BF tones at $20 \mathrm{~dB}$ and $30 \mathrm{~dB}$ suprathreshold.

physiological response profile is shown in Figure 2. On-C axons (black) branched profusely, forming a local plexus of fine branches with boutons en passant and terminaux. Although some of the local ramification was present in the same volume as the dendritic arbor (red), the local axonal termination was 

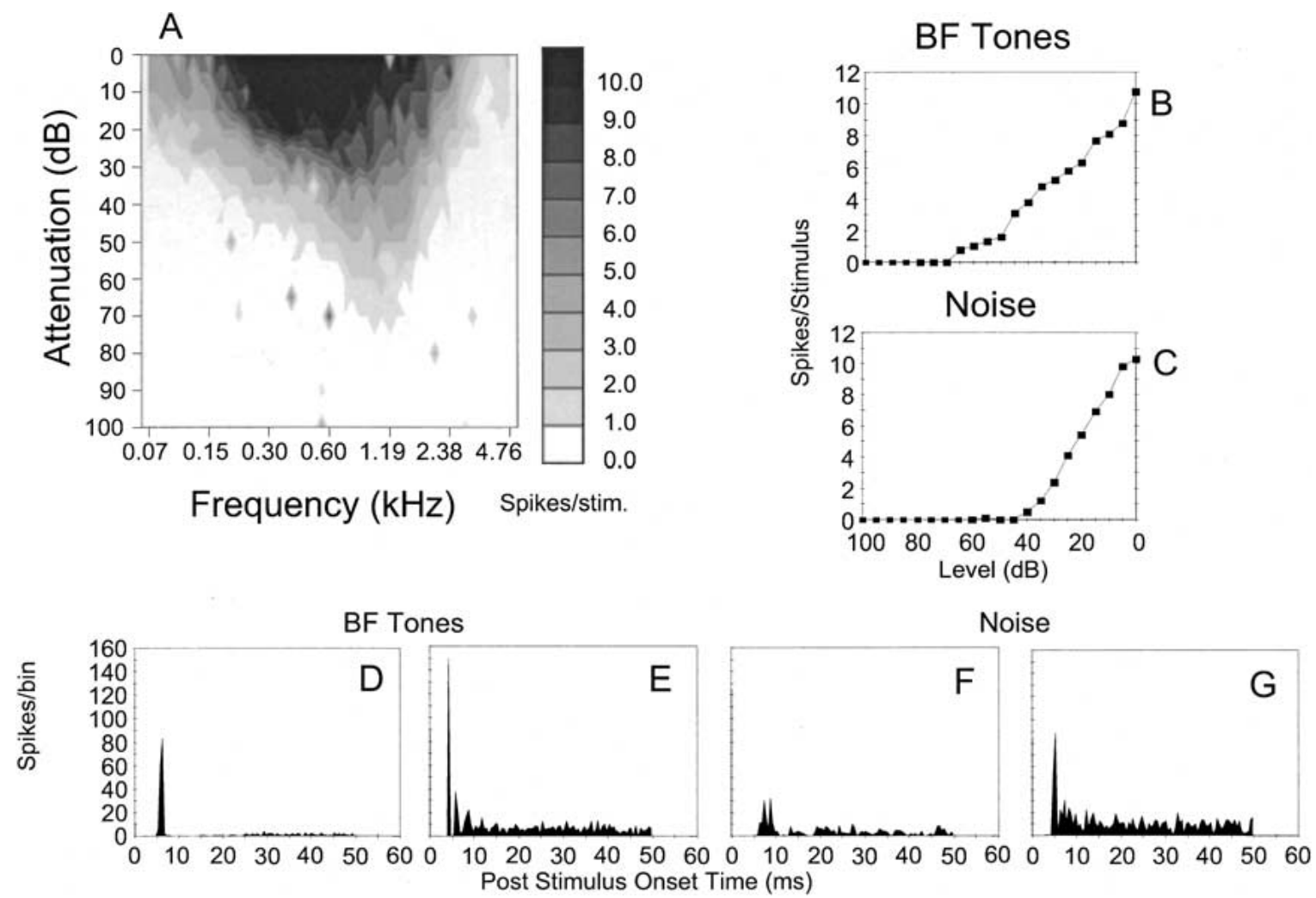

FIG. 4. Physiological characteristics of unit 249 (BF-1.2 kHz) identified as an On-C type. A Frequency response area. B, C Discharge rate versus level function showing mean $( \pm$ SEM) number of discharges per stimulus. The ordinate shows attenuation in decibels below maximum output for BF tones $(\mathbf{B})$ and broadband noise $(\mathbf{C})$. D,

more extensive and, in every case, innervated regions of the AVCN which were outside those containing the cell's dendrites (Figs. 5-7). Despite the length of the axon, for all four of the reconstructed On-C cells, local terminations appeared to be arranged largely within a volume of tissue representing BFs that were within 1 octave of the injected cell's BF. They appeared to be centered on the same isofrequency slab as the dendrites (Fig. 9A,B).

There was some variability in the pattern of local termination. For example, the local axonal ramification of the neurone in Figures 5 and 9A (No. 282, BF$6.3 \mathrm{kHz}$ ) is arranged in a diagonally oriented cylinder whose axis is displaced medially and rostrally from the soma. In contrast, the local innervation of the other On-C cells is arranged more diffusely (Figs. 6, 7, 9B).

Axon terminations in PVCN. Three of the On-C cells gave rise to varicose axonal plexuses in the most caudal part of PVCN. However, the route by which the axon reached the PVCN differed in each of our reconstructed neurones. In the neurone in Figure 5 (No. 282, BF-6.3 kHz), a branch of the ipsilateral DCN innervation turned ventrorostrally to arborize in the caudoventral part of PVCN (see arrows) beneath
E PSTHs compiled from 150 presentations of $50 \mathrm{~ms}$ BF tone bursts, which were delivered at $20 \mathrm{~dB}$ and $50 \mathrm{~dB}$ suprathreshold. Binwidth$1 \mathrm{~ms}$. F, G Similar PSTHs compiled from responses to bursts of broadband noise delivered with $30 \mathrm{~dB}$ and $10 \mathrm{~dB}$ of stimulus attenuation (cf. C).

the ventral boundary of rostral DCN. In contrast, in the neurone shown in Figure 6 (No. 212, BF$5.9 \mathrm{kHz})$, an axonal branch arose from the local arbor and projected caudoventrally, giving rise to a varicose axonal plexus in the same caudoventral region of PVCN (indicated by arrows). Interestingly, a further axonal branch arose from this PVCN plexus and extended back rostrodorsally, running along the lateral margin of the $\mathrm{CN}$ to terminate within the volume of the neurone's local axonal arbor. The neurone in Figure 7 (No. 249, BF-1.2 kHz) innervated the same region of PVCN (see arrows) via terminating branches of the axon en passage to the ipsilateral DCN. Only the PVCN innervation of unit 212 (Fig. 6) gave rise to the recurrent fiber that extended rostrally to re-enter AVCN.

In AVCN, PVCN, and DCN, when there was sufficient background labeling, it was possible to see the terminal branches of an On-C axon encircling pale somata and giving rise to en passant and terminal varicosities in close proximity to them (Fig. 8B).

Axon terminations in DCN. The axons of all five On-C cells entered the dorsal acoustic stria and gave rise to branches that innervated the ipsilateral DCN. 


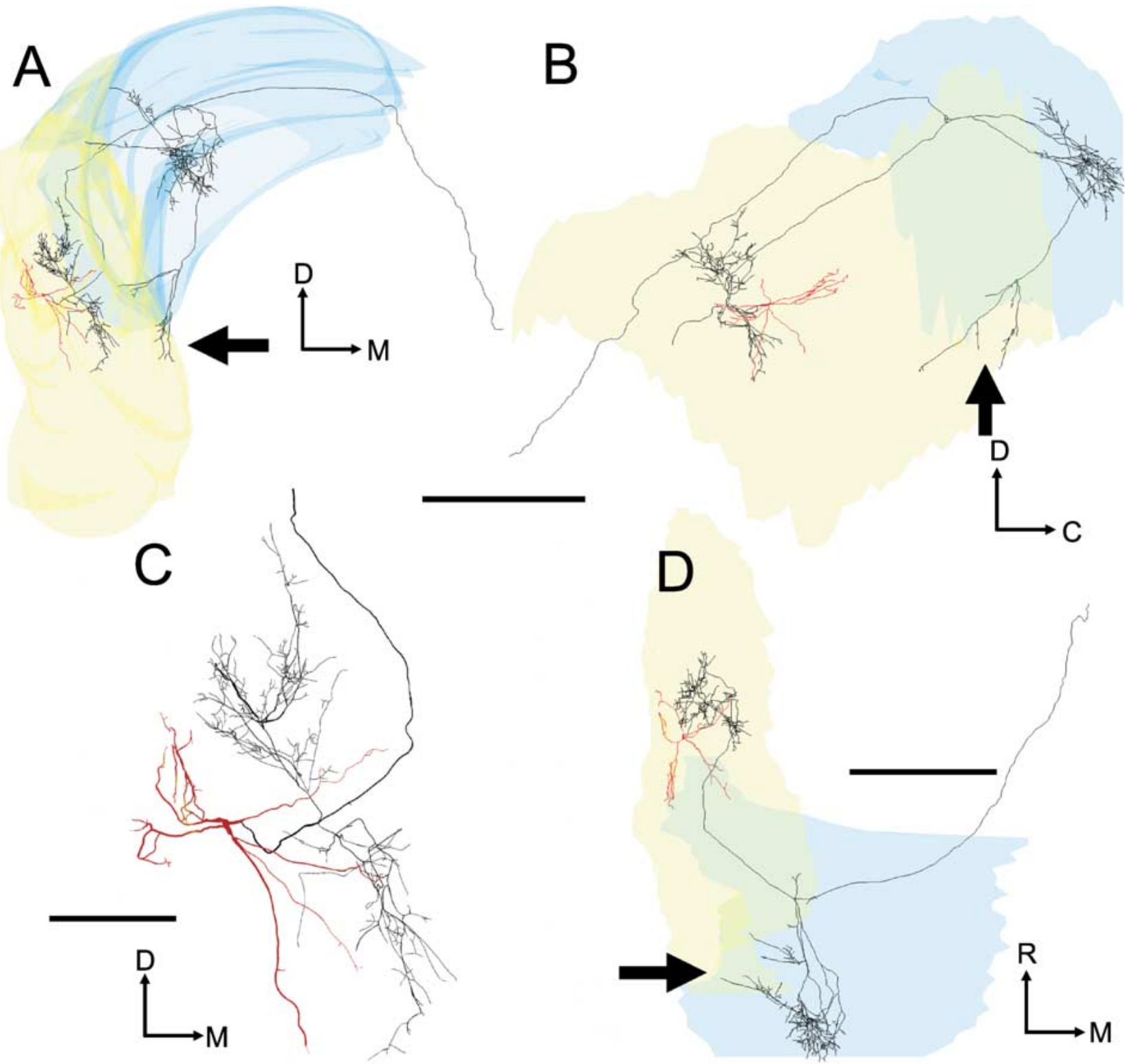

FIG. 5. Three-dimensional tracing of the soma and dendrites (red) and the axon (black) of the On-C cell (unit 282, BF-6.3 kHz) related to the outlines of the left cochlear nucleus (rendered semitransparently). The surface rendering of DCN (blue) and VCN (yellow) overlaps in places to form a denser color. A Transverse view seen from the caudal pole. B Sagittal view seen from the lateral aspect. C Higher-power transverse view showing the dendrites and local axon in high-quality mode which represents the actual thickness of the axon and dendrites. D Plan view looking down on the dorsal surface.

The axon formed profuse, varicose branches that crossed almost the whole dorsoventral extent of DCN. These branches occupied a segment of approximately one-third of the mediolateral extent of the nucleus, and approximately one-half of the rostrocaudal extent. There are differences in the location of the DCN termination of the low-BF On-C cell (No. 249, BF$1.2 \mathrm{kHz}$, Figs. 7, 10A) compared with the termination of two neurons with higher BFs (No. 212, BF-5.9 kHz,
In this (A, B, and $\mathbf{D})$ and similar tracings, the neuronal processes are rendered with disproportionate, uniform thickness so that they are visible within the small-scale drawings of the cochlear nucleus. The main axon crosses the midline (Fig. 11), while other branches form a varicose arbor in the ipsilateral DCN (Fig. 10C). A few fibers also terminate in the posterior $\mathrm{VCN}$ (see arrows). Scale bar for A, B, $\mathbf{D}=1000 \mu \mathrm{m}$ and for $\mathbf{C}=250 \mu \mathrm{m}$. Abbreviations for this and subsequent figures: C, caudal; D, dorsal; $M$, medial; $R$, rostral.

Figs. 6, 10B and No. 282, BF-6.3 kHz, Figs. 5, 10C). These are consistent with their differences in BF. The low-frequency unit (No. 249, Fig. 10A) gave rise to extensively arborized and terminating fibers which were found primarily in the low-frequency ventrolateral portion of DCN. In contrast, the higher-frequency units (No. 212, Fig. 7B and No. 282, Fig. 7C) terminated primarily in the higher-frequency central portion of DCN. 


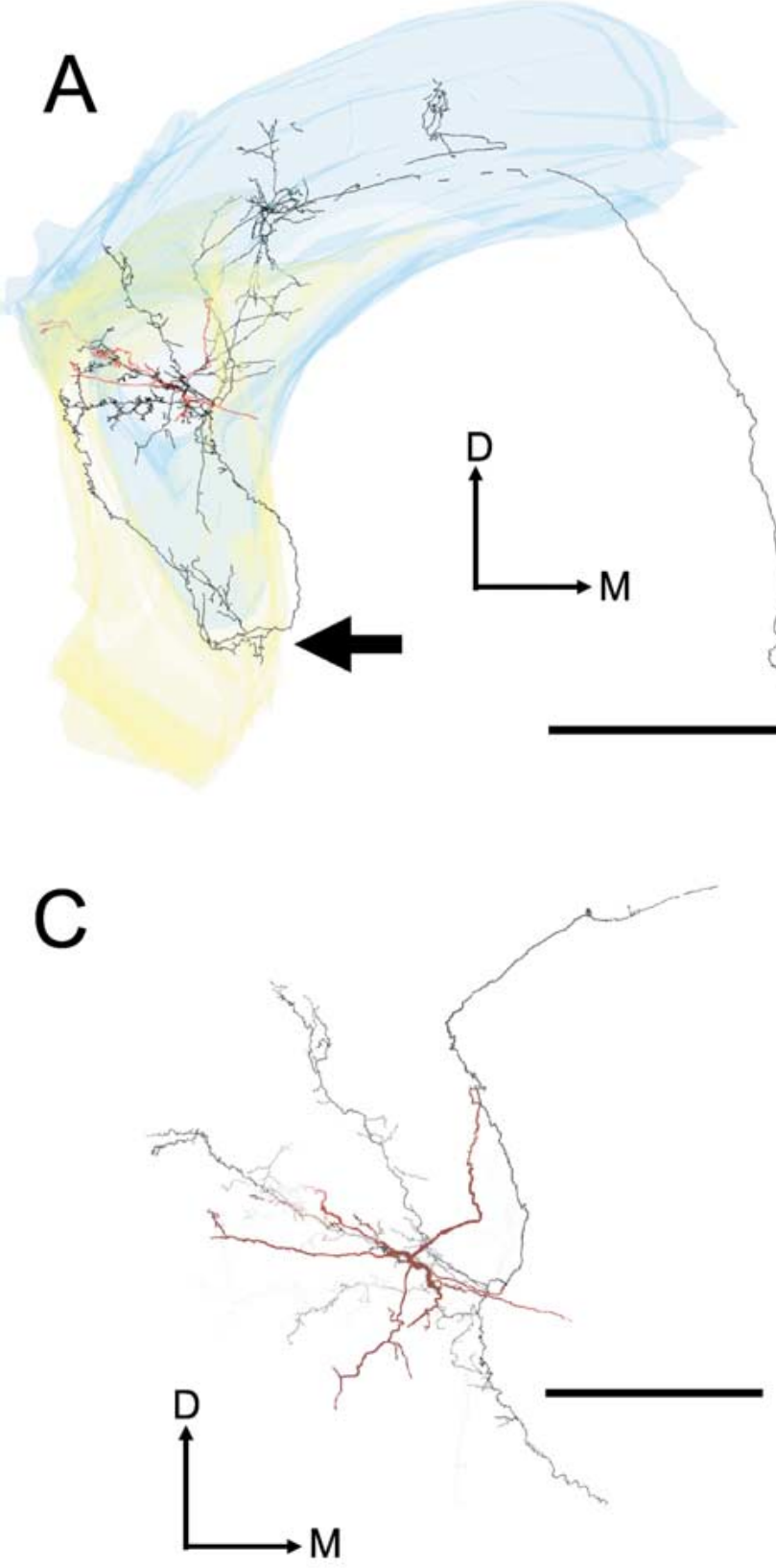

FIG. 6. Four images of the soma and dendrites (red) and the axon (black) of the On-C cell (unit 212, BF-5.9 kHz). A Transverse view. B Sagittal view. C Higher-power transverse view showing the dendrites and local axon in high-quality mode and with "depth cueing" switched on. Processes rostral to the soma become increasingly pale with increasing distance away from the soma. D

Contralateral projections. It was possible to trace four of the On-C axons as they continued to course medially in the dorsal acoustic stria. In three cases the axons faded after $2-4 \mathrm{~mm}$ and could not be traced beyond the midline. In unit 282 (Fig. 11), however, it was possible to trace the axon throughout its course from the dorsal acoustic stria beneath the ipsilateral DCN until it reached its termination in the contra-
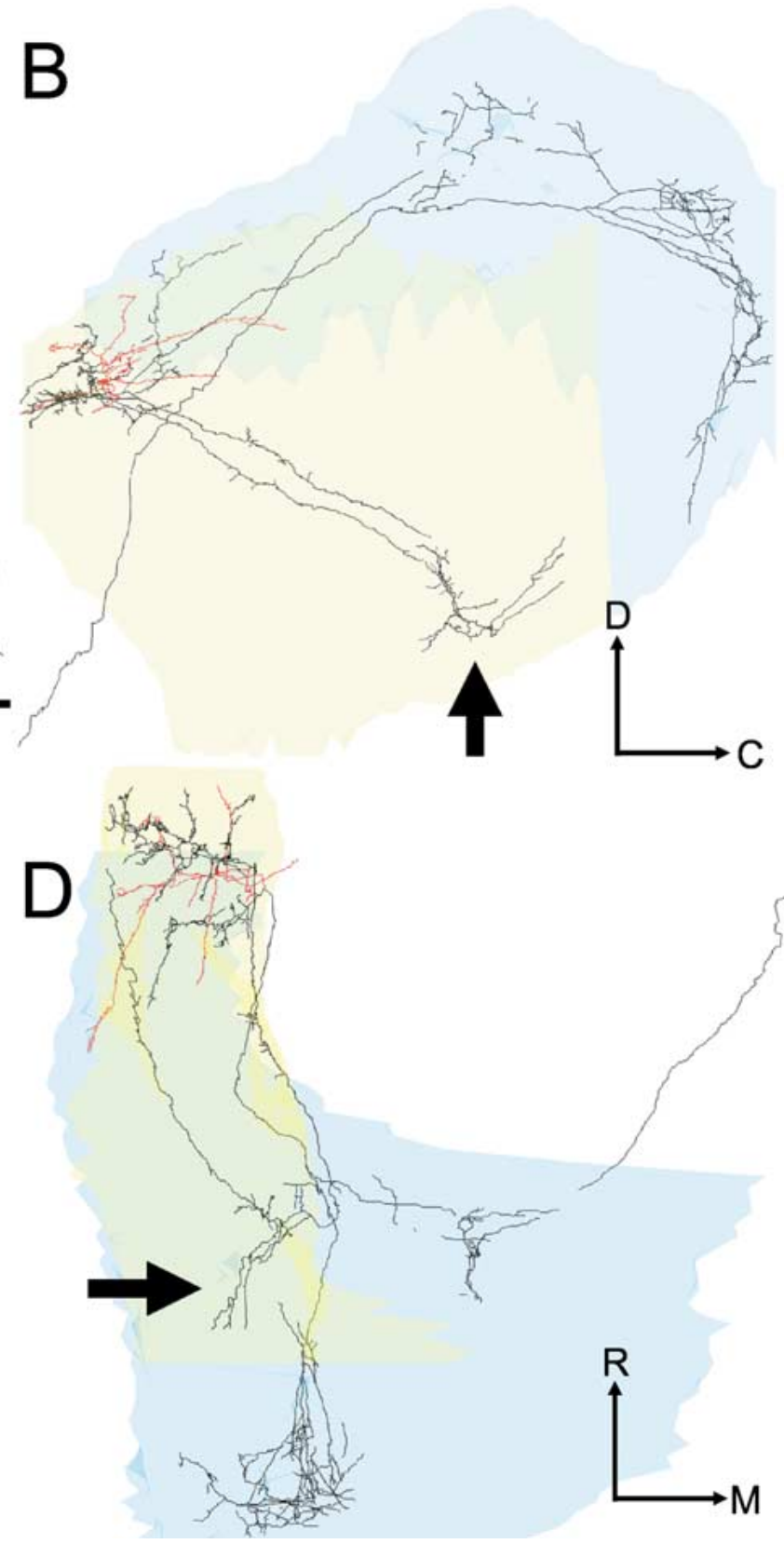

Plan view. Scale bar for A, B, D $=1000 \mu \mathrm{m}$ and for $\mathbf{C}=500 \mu \mathrm{m}$. The axonal branch which directly innervates the caudal PVCN is clearly visible in all three orientations of the tracing (see arrows). This pattern contrasts with the course taken by the PVCN innervation of unit 282 (Fig. 5), which had similar BF but was located more caudally in AVCN.

lateral DCN. This axon coursed rostromedially in the white matter beneath the fourth ventricle. It reversed its course at a point several hundred microns rostral to the plane of the On-C soma before running caudally again. The fiber then entered the contralateral DCN, giving rise to a bifurcating, varicose process that extended across the mediolateral width of the nucleus. Although present during initial examination, 


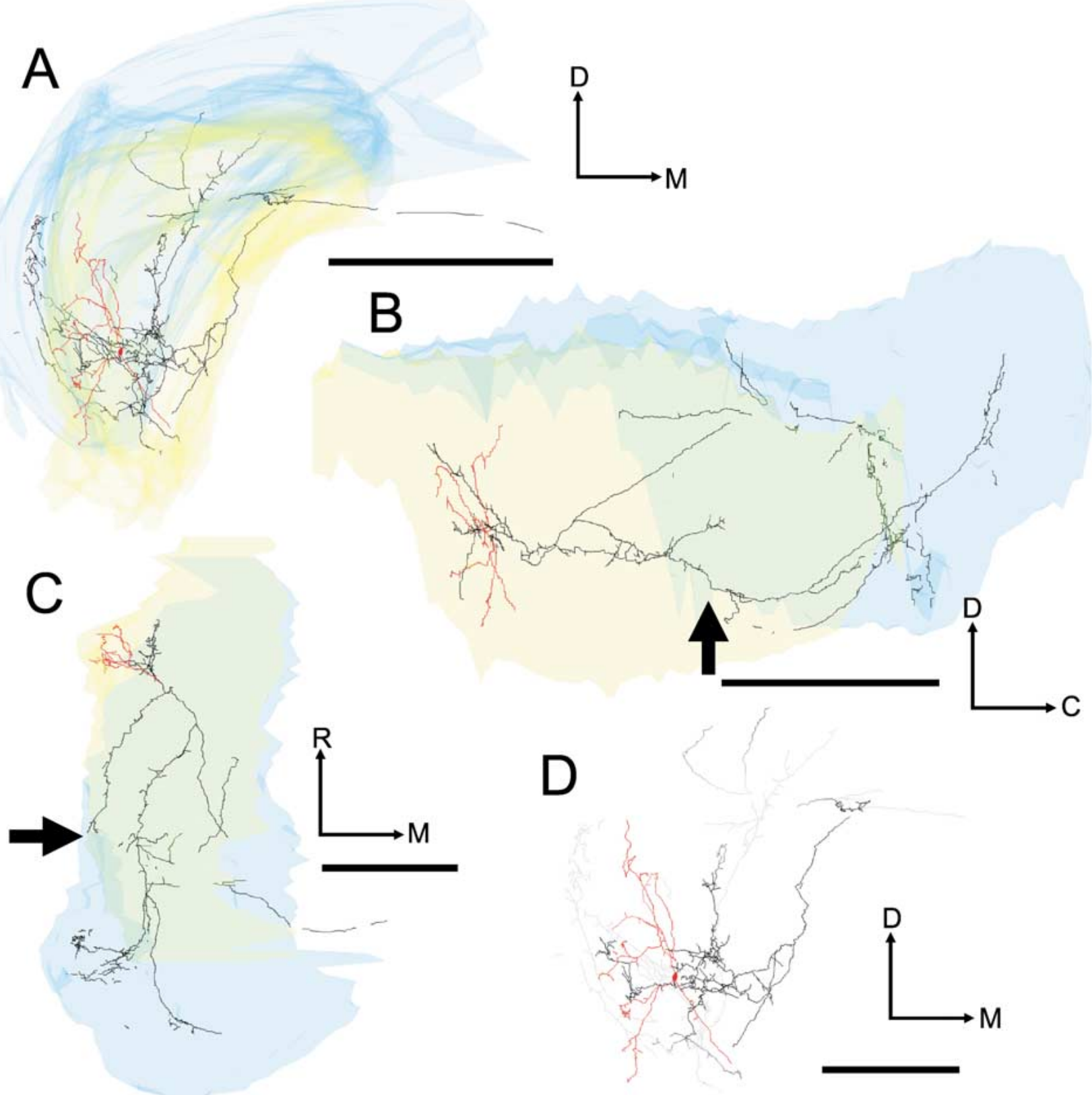

FIG. 7. Four images of the soma and dendrites (red) and axon (black/gray) of unit 249 (BF-1.2 kHz). A Transverse view. B Sagittal view. C Plan view. D Higher-power transverse view showing the dendrites and local axon in high-quality mode and with "depth cueing" switched on. Scale bar for A, B, C = $1000 \mu \mathrm{m}$ and for $\mathbf{D}=500 \mu \mathrm{m}$. A branch of the local axonal arbor passed through

fading of the reaction product meant that these fine terminal fibers could not be traced in our reconstruction.

The contralaterally projecting axonal branches were traced from section to section. There was no evidence of axonal branching either before the neurone became untraceable in the heavily myelinated fiber tract beneath the fourth ventricle or, in the case ventral PVCN, where it gave rise to a small plexus of terminating fibers (see arrows), en passage to the most ventrolateral part of the ipsilateral DCN. In common with the other On-C neurones in our sample, it was possible to trace a stained axon in the DAS which projected toward the midline.

of unit 282, before the fiber innervated the contralateral $\mathrm{CN}$.

\section{On-L neurones}

Physiological responses. Two of our labeled neurones had On-L characteristics as defined by Winter and Palmer (1995). An example physiological profile is 

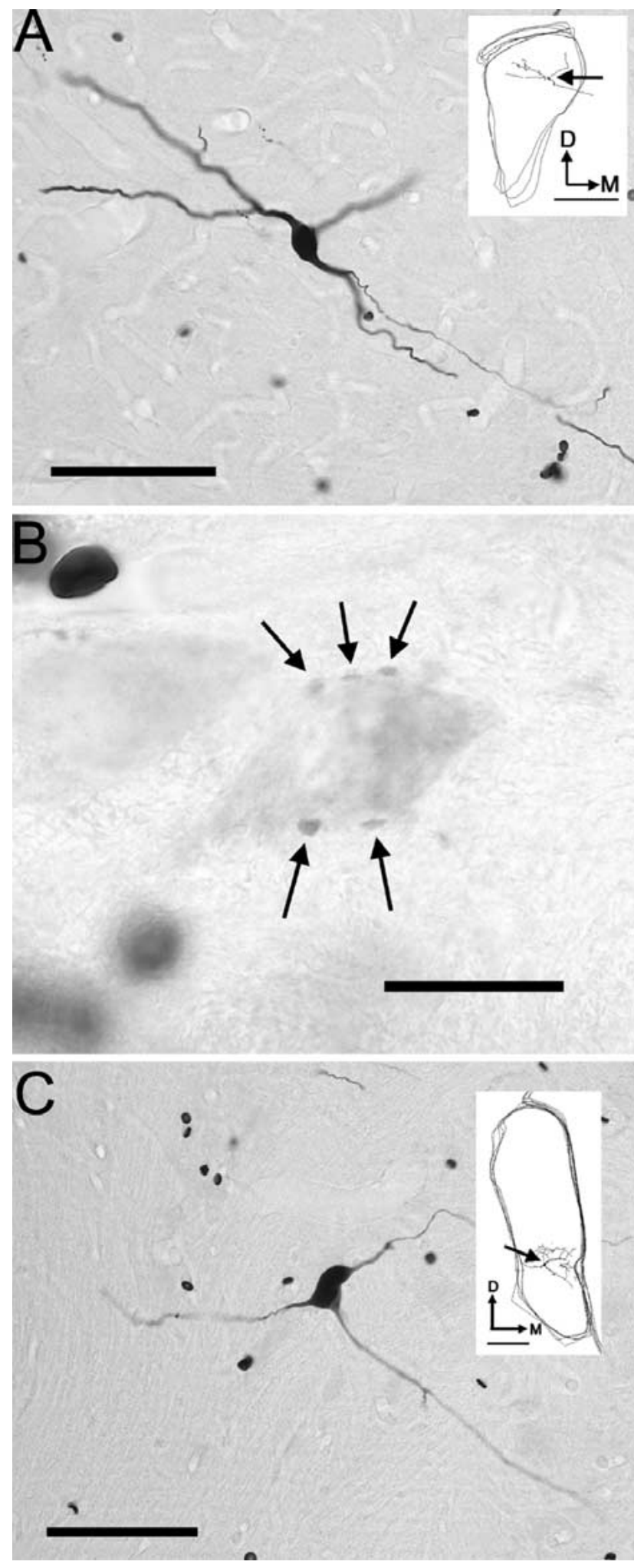

shown in Figure 12. Their responses to BF tones at levels of 20 and $50 \mathrm{~dB}$ suprathreshold gave rise to PSTHs which showed only a single peak at the onset of the stimulus (Fig. 9D,E), but otherwise were quite similar to On-C responses. In response to increasing
FIG. 8. A Photomicrograph of the soma of On-C unit number 212 (BF-5.9 kHz) showing the thin axon arising from the ventral dendrite; scale bar $=100 \mu \mathrm{m}$. Inset is a tracing of three sequential sections of AVCN. The position of the soma is indicated by the arrow; inset scale bar $=500 \mu \mathrm{m}$. B Pale soma in PVCN, revealed by background staining, which is surrounded by a number of stained boutons (arrows). Scale bar $=20 \mu \mathrm{m}$. C Photomicrograph showing the soma and proximal processes of On-L unit 284 (BE-10.9 kHz); scale bar $=100 \mu \mathrm{m}$. Inset shows the position of the soma (arrow) and local processes of the neurone within the traced outline of the $\mathrm{CN}$. Inset scale bar $=200 \mu \mathrm{m}$.

levels of wideband noise stimuli, they showed more than one peak at the stimulus onset (see Fig. 9F,G).

Anatomical Arrangement. Whereas we were unable to distinguish the soma and dendrites of the On-L cells from those of our On-C cells, there were differences in their axonal projection. The somata were ovoid and gave rise to gently tapered, aspinous dendrites that were finely branched at their terminations. Unit 286 gave rise to four primary dendrites (total length-6970 $\mu \mathrm{m}$ ); unit 284 gave rise to six primary dendrites (total length-7096 $\mu \mathrm{m}$ ).

Like the On-C cells, our On-L cells gave rise to local, extensively branched, varicose axonal processes which innervated a volume which was more extensive than that occupied by the cells' dendrites (Fig. 9C,D). The local axonal tree was flattened orthogonal to the frequency axis of the nucleus. This flattening meant that the axon was largely located among cells with BFs that were less than one octave above that of the injected cell.

One of the On-L cells gave rise to axonal processes which innervated the ventral part of PVCN. This input was via two axonal branches arising from the local axonal arbor and projecting caudally into the most rostral part of ventral DCN, giving rise to short, terminating branches as they traversed caudal PVCN (Fig. 13; No. 284, BF $=10.9 \mathrm{kHz}$ ). The other On-L cell also had caudally directed local axonal branches, but these innervated caudal AVCN and did not reach PVCN.

The ipsilateral DCN was innervated extensively by the On-L cells. In common with the On-C cells, the local axonal arbor gave rise to a fiber which projected medially to run dorsocaudally in the white matter which forms the medial border of $\mathrm{CN}$. The fiber branched upward from the dorsal acoustic stria (DAS) to form a highly branched plexus of fine varicose axonal fibers in the DCN. This plexus extended through virtually the whole dorsoventral thickness of the DCN and, in contrast to the On-C neurones, one of the On-L cells (No. 284) innervated approximately two-thirds of the ventromedial width of the nucleus (Fig. 14 A). Whereas the fine axonal branches gave 


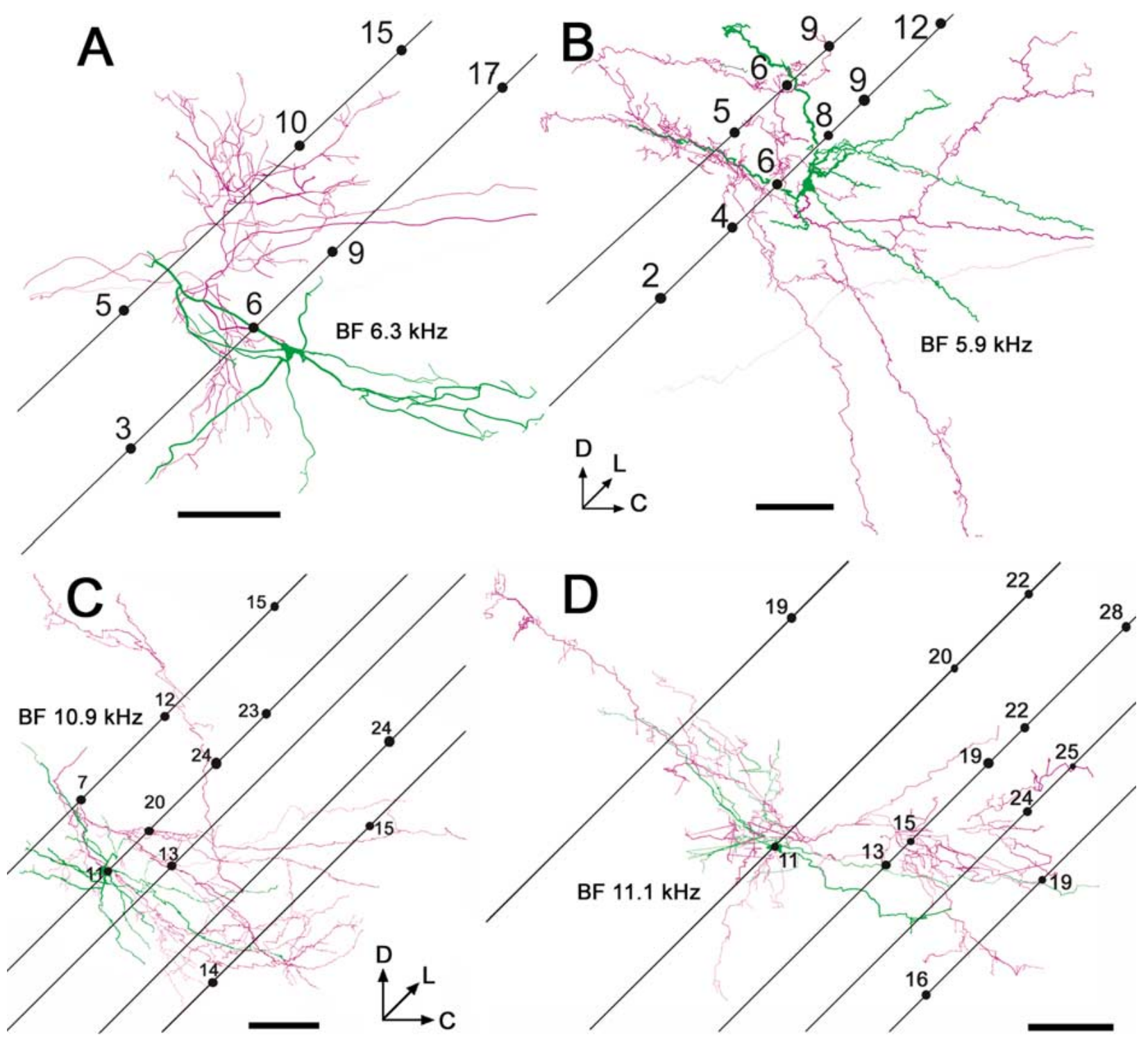

FIG. 9. Reconstructions of the soma and dendrites (green) and the proximal axon (magenta) of onset units viewed in the sagittal plane. In each case, the positions of associated electrode tracks are superimposed to indicate the frequency gradient within AVCN. The electrodes were inserted at $45^{\circ}$ relative to the horizontal stereotaxic plane (as defined by Rapisarda and Bacchelli 1977), and the angle of the tracks was found by reconstructing them along with the labeled cells. Subsequently, for these four cells the orientation was defined in relation to the electrode tracks and not to the histological section. Some tracks were clearly visible over part of their course because of

rise to varicosities throughout their length, as they traversed DCN the fibers formed a more heavily branched band of termination in the superficial third of DCN, below the most superficial layer of the nucleus. This pattern contrasts with those of the other On-L (Fig. 14B) and On-C terminal branches, which were more evenly distributed throughout the thickness of the DCN (cf. Fig. 10). blood entering them after removal of the electrode. Numbers on the tracks indicate the BFs of recorded units in $\mathrm{kHz}$. The reconstructed images are shown with "depth cueing" so that processes that are deep to the plane of the figure become increasingly faint, while processes that come out of the page toward the viewer are made darker. A On-C unit 282, BF-6.3 kHz B On-C unit 212, BF-5.9 kHz; C On-L unit 284, BF-10.9 kHz; D On-L unit 286, BF-11.1 kHz. In this figure neuronal processes are rendered with their fiber thickness in correct proportion. Scale bars $=200 \mu \mathrm{m}$.

Three-dimensional reconstruction necessitated tracing every axonal branch using the $40 \times$ lens. In neither of our fully reconstructed On-L cells was there any evidence of axonal projection toward the midline as shown by the five On-C cells. The On-L axons were darkly stained and we are confident that we would have seen a midline branch had one been present. 

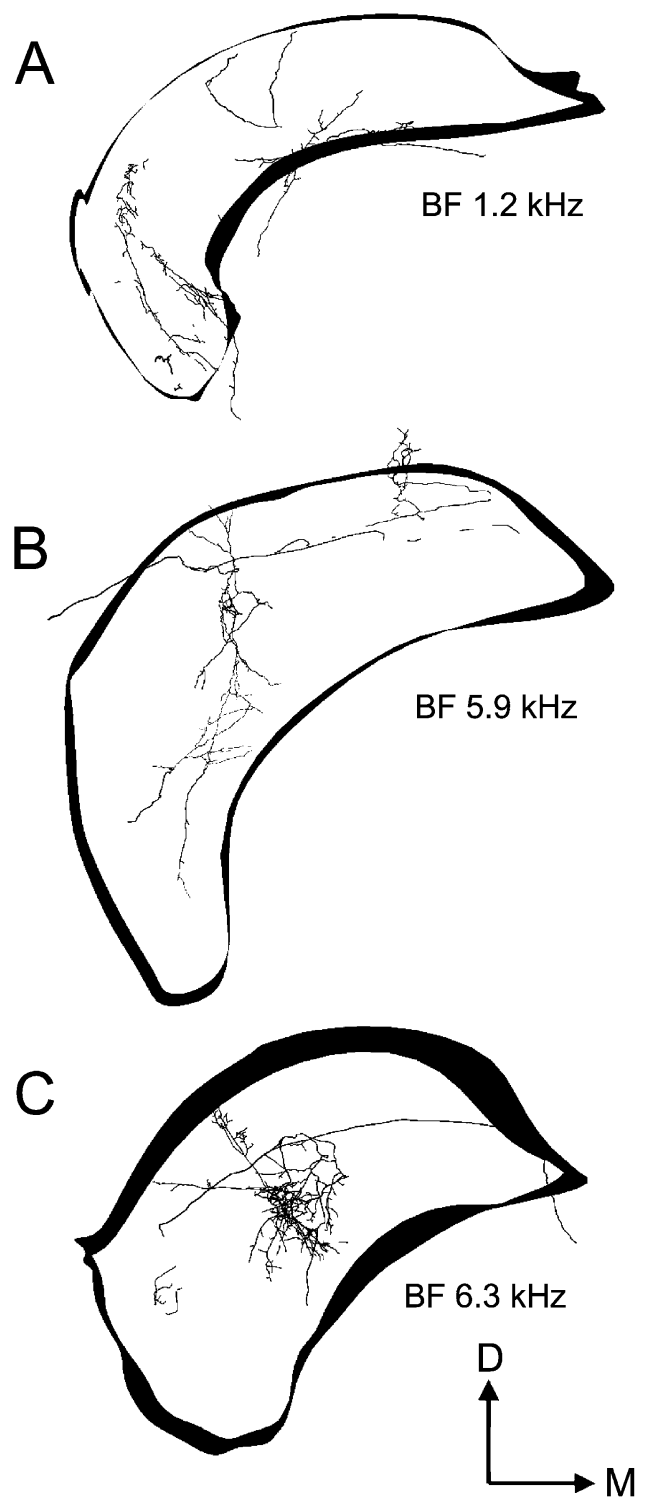

FIG. 10. Reconstructions of the innervation of the left (ipsilateral) $\mathrm{DCN}$ by axonal processes arising from three On-C cells. The outlines of the DCN are included to indicate orientation; they are shown for a very constrained rostrocaudal segment of the nucleus, whereas the flattened three-dimensional tracing of the whole of the DCN innervation is shown. In all three examples, the axonal termination occupies approximately one-third of the mediolateral extent of the nucleus while extending across virtually its entire dorsoventral thickness. In our current data, all but the most superficial part of $\mathrm{DCN}$ receives afferent input from On-C type neurones. A DCN termination of unit 249. The majority of the axonal termination is in the ventrolateral part of DCN. Neurones recorded in this part of DCN generally exhibit low BFs. B DCN termination of unit 212. The majority of the termination is in the central region of DCN, which is associated with middle-frequency neurones in DCN recording studies. C The DCN termination of unit 282 also occurs in the central region of the nucleus but is more restricted than the termination of unit 212. In these tracings, as in Figure 9, neuronal processes are rendered with their thickness correctly proportioned. Scale bar $=1000 \mu \mathrm{m}$.

\section{DISCUSSION}

In this study we used the juxtacellular labeling technique to clarify an important component of the internal circuitry of the mammalian cochlear nucleus. We have shown that the On-C/L cells are probably the same as the wideband inhibitor or radiate neurone or D-multipolar that have been described by others. Although these cells have been studied by combined anatomical/physiological methods before, we have gone beyond previous studies. Thus, we have provided a much more detailed description of the axonal distribution, both within the ipsilateral CN and also to the contralateral CN. This anatomy has been combined with both a description in vivo of the physiological response profile and attempts to relate the morphology to a detailed map of the isofrequency sheets in a way not tried before. Different aspects of the study will be discussed in turn.

\section{Local axonal projections}

Both On-C and On-L cells gave rise to substantial local axonal arbors in PVCN and AVCN. The axons into PVCN took a number of different routes, but it is presumably the locus of termination which is important and not the trajectory. For both cell types we observed terminal axonal branches forming rings or clusters of en passant and terminal varicosities that encircled somata which were not labeled specifically (Fig. 8B). This observation suggests that the On-C and On-L axons may form axosomatic synaptic contacts of the kind commonly associated with inhibitory synaptic input. This suggestion is supported by both the imrnunohistochemical evidence for glycinergic transmission in VCN large stellate cells which innervate DCN (Doucet et al. 1999; Alibardi 2001) and the presence of glycinergic terminals on the somata of fusiform cells in the DCN (Osen et al. 1990). There is also extensive physiological evidence for strychninesensitive inhibitory input to type II cells in DCN (Davis and Young 2000).

The functional role of this local inhibition can be inferred only indirectly, but there has been a proposal that broadly tuned On-C cells inhibit narrowly tuned chopper cells (Smith and Rhode 1989). There is also evidence from in vitro work that large D-type stellate cells inhibit the smaller T stellate cells. This evidence implies that widely tuned On-C cells provide choppers with inhibitory sidebands (Ferragamo et al. 1998). Pressnitzer et al. (2001) have suggested that some cell types in VCN, especially transient chopper (Chop-t)type cells, may be involved in the psychophysical phenomenon of comodulation masking release. They have constructed a model circuit that depends upon wideband inhibitory input, which is similar to that in 


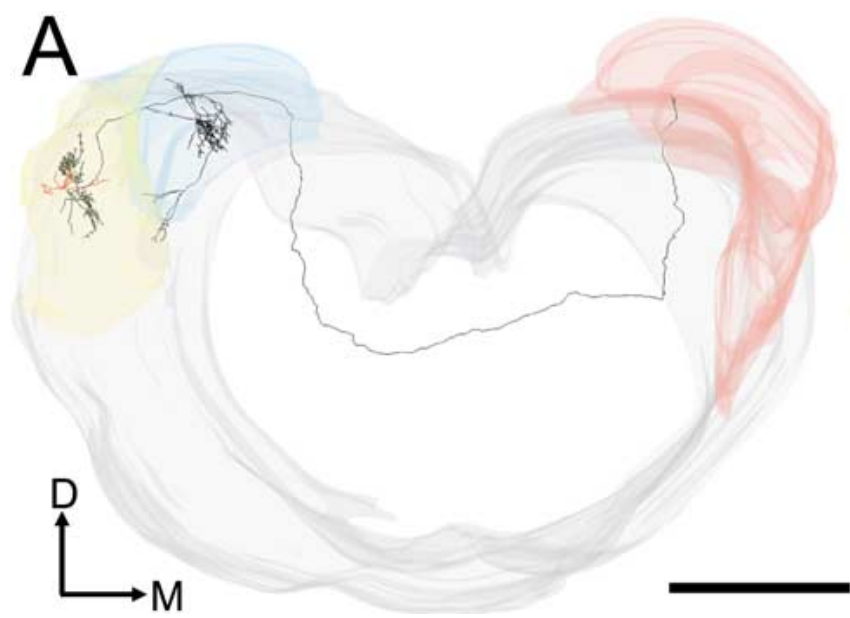

FIG. 11. Two views of the same tracing of unit 282 (BF-6.3 kHz). A Partially rotated coronal view of the brain stem including the left and right cochlear nuclei. The axon (black) arose from the base of one of the dendrites (red) and projected into the ipsilateral DCN (blue
B

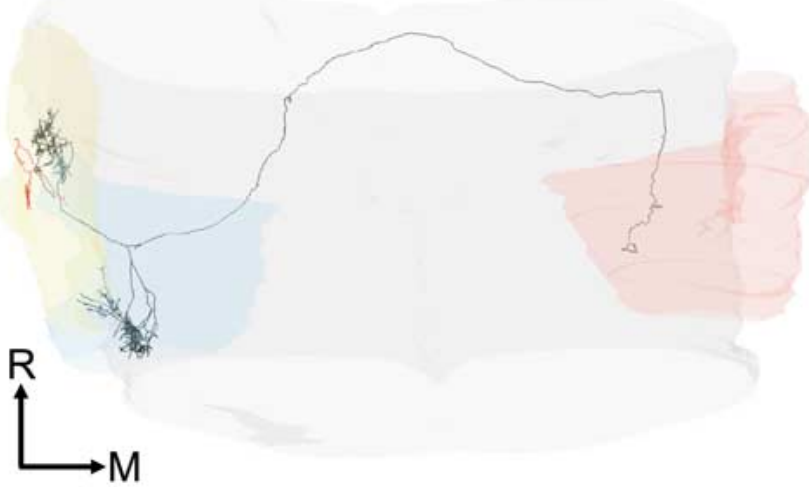

outline on left) giving rise en route to a branch which coursed rostrally and medially. B Top view of the same tracing showing the path of the axon as it innervated both the left (ipsilateral) and right (red surface contours) dorsal cochlear nuclei. Scale bar $=1000 \mu \mathrm{m}$.
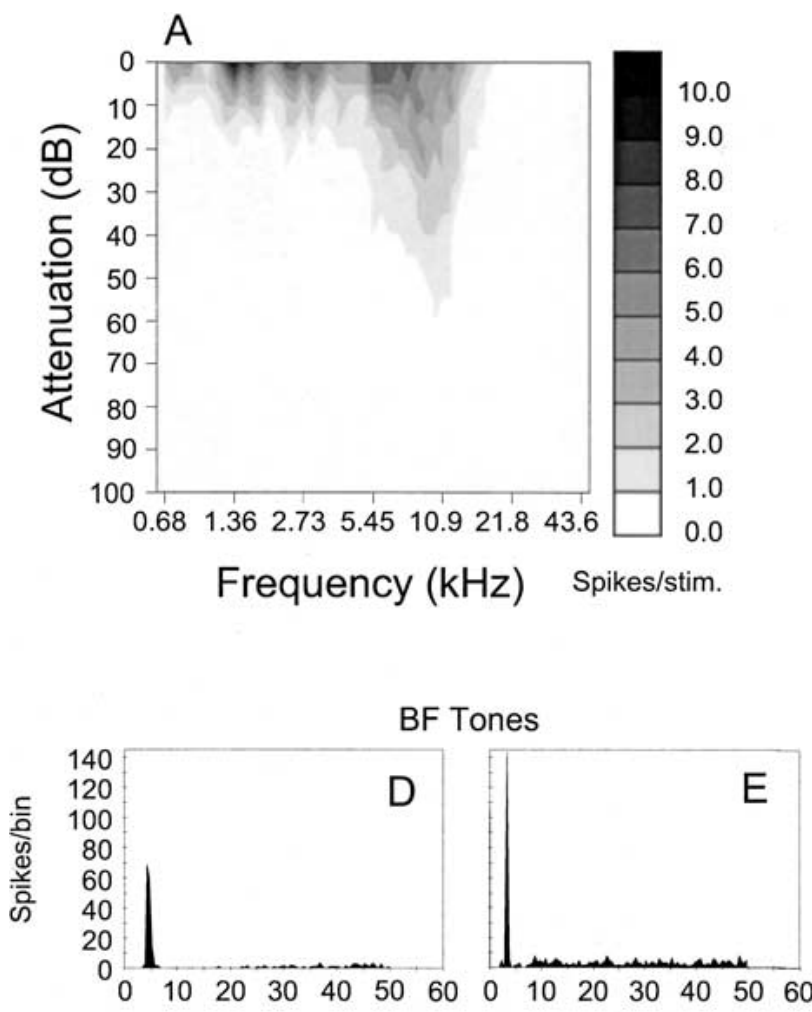

Post Stimulus Onset Time (ms)
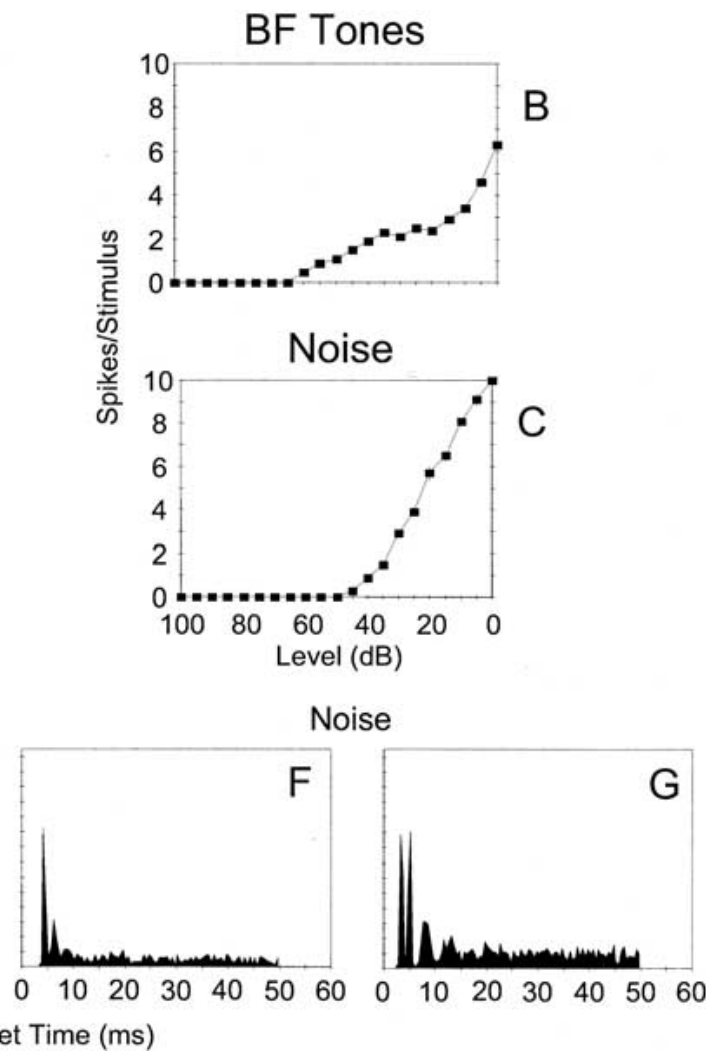

FIG. 12. Physiological characteristics of unit $284(\mathrm{BF}-10.9 \mathrm{kHz})$ identified as an On-L type. A Frequency response area. B, C Discharge rate versus level function showing mean $( \pm$ SEM) number of discharges per stimulus. The ordinate shows attenuation in decibels below maximum output for BF tones $(\mathbf{B})$ and broadband noise $(\mathbf{C})$. D,

DCN. Both the On-C and On-L cell types may provide the basis of such an inhibitory circuit through their local projections into AVCN and PVCN. Only the On-L
E PSTHs compiled from 150 presentations of 50 ms BF tone bursts, which were delivered at $20 \mathrm{~dB}$ and $50 \mathrm{~dB}$ suprathreshold. Binwidth$1 \mathrm{~ms}$. F, G Similar PSTHs compiled from responses to bursts of broadband noise delivered with $20 \mathrm{~dB}$ and $0 \mathrm{~dB}$ of stimulus attenuation (cf. C).

cells in our study innervated rostral AVCN (probably because of their position within the nucleus), but there is no evidence to suggest that this connection is 


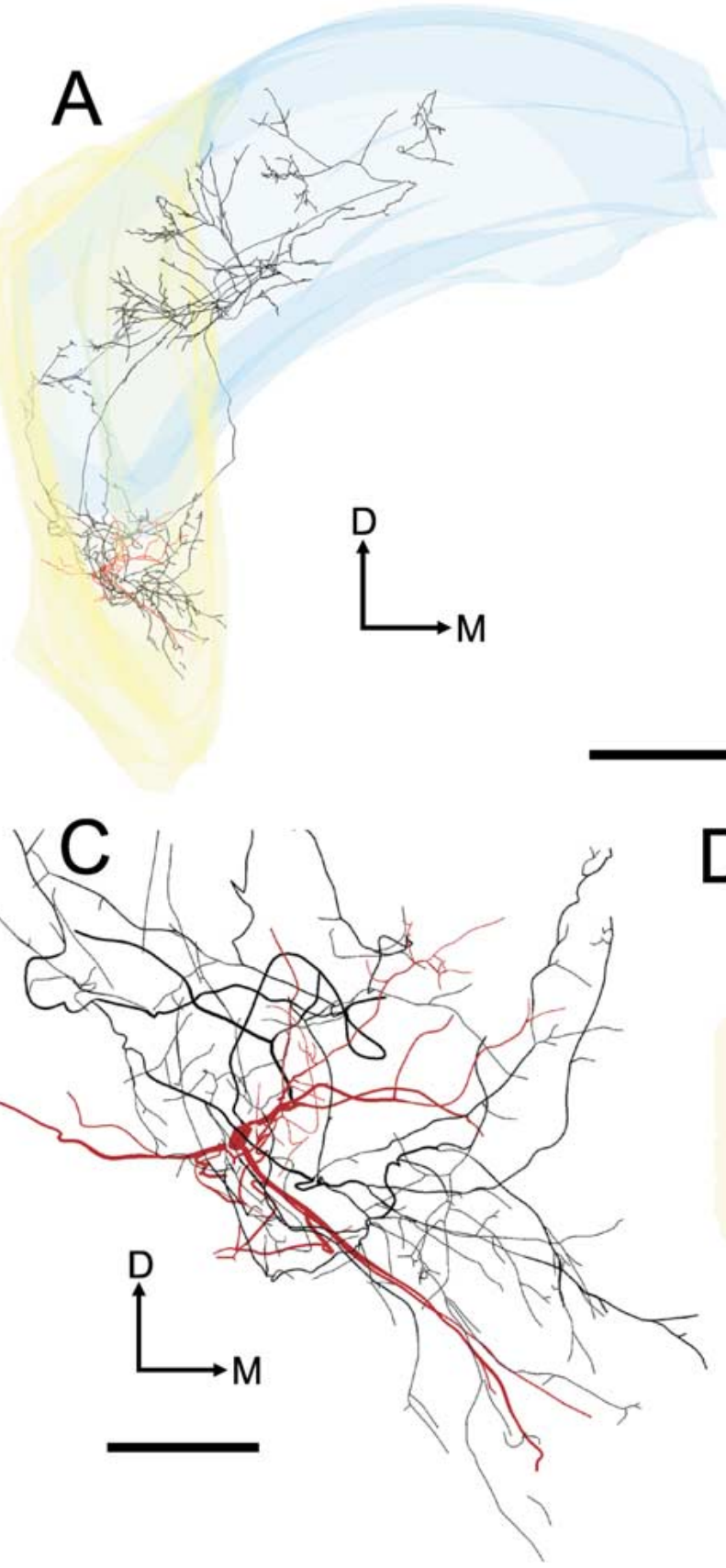

FIG. 13. Four images of the soma and dendrites (red) and the axon (black) of the On-L cell (unit 284, BF-10.9 kHz). A Transverse view. B Sagittal view. C Higher-power transverse view showing the dendrites and local axon in high-quality mode. D Plan view. Scale bar for $\mathbf{A}, \mathbf{B}, \mathbf{D}=1000 \mu \mathrm{m}$ and for $\mathbf{C}=250 \mu \mathrm{m}$. Like the On-C neurones, this cell gave rise to a profuse local axonal innervation. Additionally, the cell gave rise to an axonal branch that terminated

functionally different from that to PVCN (Osen 1969; Hackney and Pick 1986).

\section{Innervation of the ipsilateral DCN}

Every labeled onset cell gave rise to projections into the ipsilateral DCN. Our sample of neurones suggests
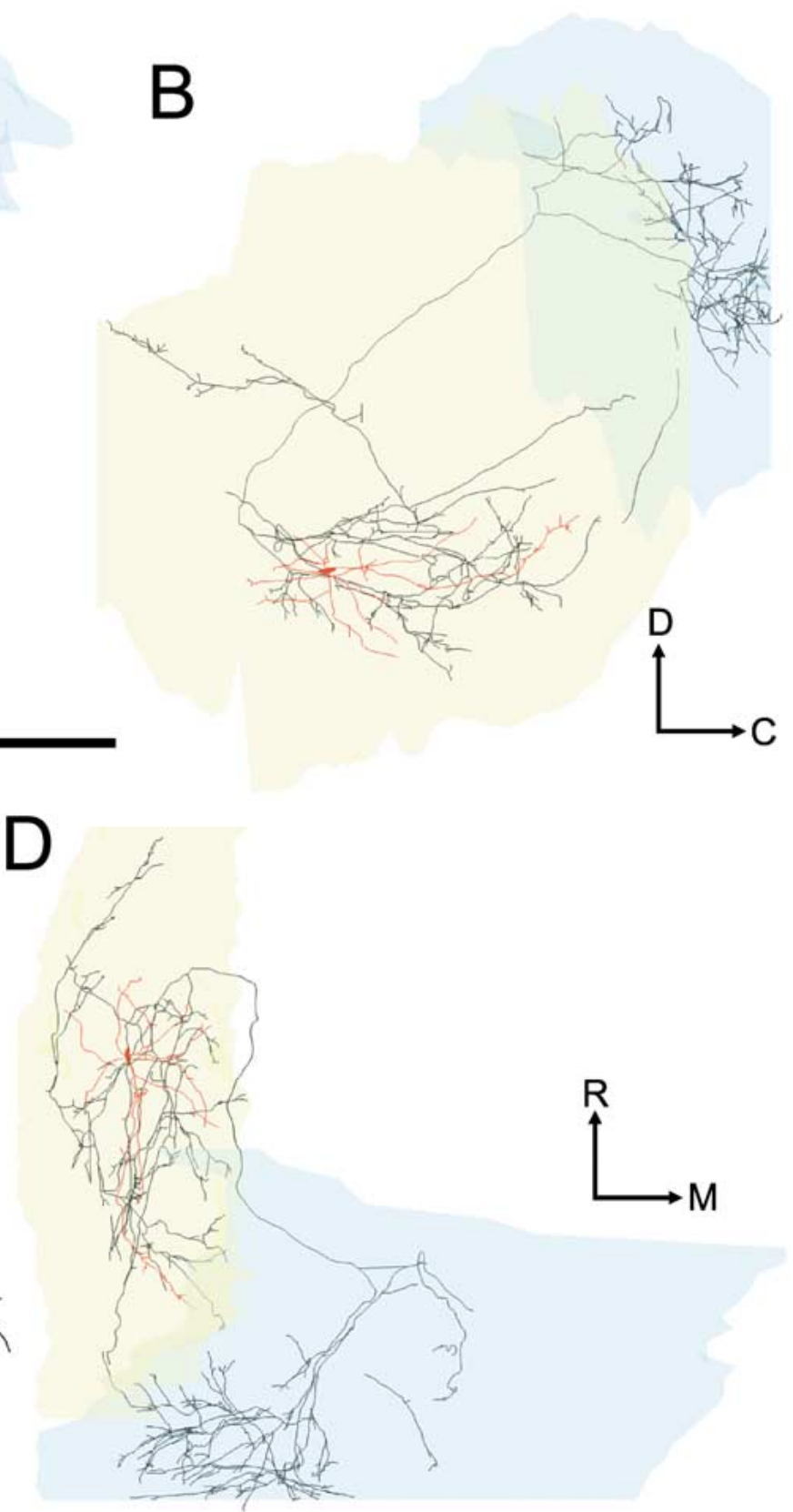

in the caudal part of PVCN. The locally ramifying axon gave rise to two further branches, one of which entered and branched profusely in the ipsilateral DCN. In contrast to our On-C cells, the second axonal branch terminated in the rostral AVCN. Also, in contrast to our On-C cells, there is no evidence of a projection beyond the ipsilateral $\mathrm{CN}$.

that there may be a tonotopic arrangement of the DCN termination of onset neurones. The DCN termination of the lowest-frequency On-C cell (unit $249, \mathrm{BF}=1.2 \mathrm{kHz}$ ) was found predominantly in the most lateral portion of the DCN, while midfrequency On-C cells gave rise to DCN terminations which were predominantly in the central portion of the 


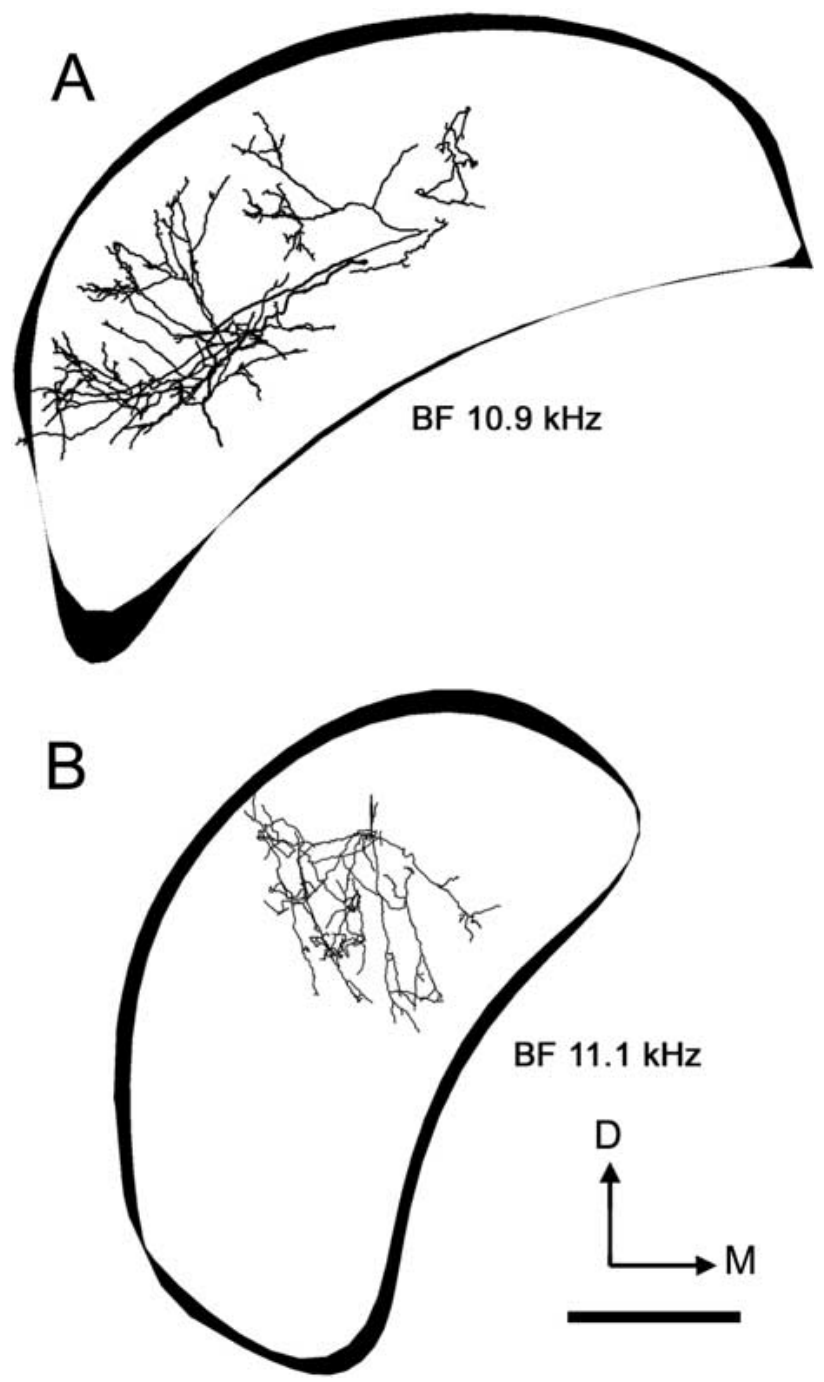

FIG. 14. Reconstructions of the innervation of the left (ipsilateral) DCN by axonal processes arising from two On-L cells. The outlines of three sections of the DCN are included to indicate orientation. A Unit 284. B Unit 286. Scale bar $=500 \mu \mathrm{m}$.

nucleus. Previous studies have shown that cells with high BFs are located most medially in DCN, and lowBF cells are located laterally and ventrally in DCN (e.g., guinea pig: Stabler 1991; cat: Spirou et al. 1993). On-C cells therefore have a projection to the DCN that, while widespread, is nevertheless loosely consistent with the tonotopicity of the DCN principal cells.

The two reconstructed On-L cells show a similar pattern of DCN termination to that seen in On-C cells, although the terminal branches of the On-L neurones appear to occupy a more constrained laminar profile. Studies of the origin of the DCN projection to the inferior colliculus have identified the principal output neurones, which are large fusiform pyramidal and giant cells, as being located predominantly in layers II, III, and IV (Ryugo and Willard
1985; Spirou et al. 1993); thus these projection cells are likely to receive input from both On-C and On-L cells.

The innervation of the DCN by the VCN has been studied using small, focal injections of retrograde tracers into the DCN (rat: Doucet and Ryugo 1997; cat: Ostapoff et al. 1999). These studies have revealed both a restricted band of labeling in the VCN that corresponds tonotopically with the frequency sensitivity of the DCN injection site and labeling of large stellate somata outside the labeled band. Retrogradely labeled VCN somata included stellate cells but not bushy cells.

Within the band of label in the VCN, stellate cells are relatively small and are oriented in the plane of the tonotopic lamina (Doucet and Ryugo 1997; Ostapoff et al. 1999), while stellate cells, outside the band of label (sometimes very far removed from the labeled band), are large and have been described as "giant" (Ostapoff et al. 1999) or "radiate" (Doucet and Ryugo 1997). Not only are the stellate cells that give onset-type responses large and have morphologies consistent with those of "giant/radiate" cells, but the widespread innervation of the DCN by our onset cells means that onset cells from divergent frequency regions would likely have been labeled by focal DCN injections. Results from previous studies in this laboratory have shown consistency between the position of onset cells with different BFs and the tonotopic arrangement of the nucleus (see Fig. 4 and Jiang et al. 1996).

The functional significance of onset cell innervation of the DCN

Important functions that have been attributed to the DCN include extraction and processing of information pertaining to sound source location (Davis and Young 2000) and speech formants (Rhode and Greenberg 1994a, b). Principal output neurones of the DCN, termed type IV or fusiform neurones, have been found to be extremely sensitive to the frequency position of sharp spectral notches (for review see Young and Davis 2002). The ability of type IV neurones to signal these important stimulus characteristics depends upon neuronal circuitry intrinsic to the cochlear nucleus complex.

A simplified schematic of this cochlear nucleus circuitry is shown in Figure 1. The cells designated as type IV and type II are classified according to the extent of the inhibitory inputs revealed within their frequency-intensity response areas (Evans and Nelson 1973; Shofner and Young 1985). Example response areas of actual neurones are also shown for the types II and IV and auditory nerve (these are for illustration only: the best frequencies in these exam- 
ples are all relatively low but unrelated). The "V"'shaped response area of the auditory nerve fiber is transformed in the type II neurone by strong inhibition that overlaps at high sound levels to generate nonmonotonic responses as a function of sound level. This strong inhibition renders type II neurones insensitive to broadband signals (Young and Brownell 1976; Young and Voigt 1982; Shofner and Young 1985). Type II responses are associated with glycinergic "vertical cells" located just beneath the fusiform cell layer in DCN (Rhode 1999).

Type IV neurones have a response area that is even more restricted, often consisting of only an island of excitation severely constrained by inhibitory inputs. Hence, type IV neurones are strongly nonmonotonic as a function of tone sound level.

In addition to their type II innervation, which primarily influences behavior near the $\mathrm{BF}$, principal cells are also inhibited at frequencies far from their BF (Nelken and Young 1994) and are thus subject to wideband inhibition, which is antagonized by strychnine (Davis and Young 2000). This wideband inhibition has been postulated to modulate the responses of principal neurones both directly, through glycinergic innervation of these cells, and indirectly, through glycinergic innervation of type II DCN interneurones.

A wealth of circumstantial evidence suggests that onset responding stellate cells in the ventral cochlear nucleus may give rise to the wideband inhibition of DCN principal cells. These onset cells integrate inputs from auditory nerve fibers with a broad range of BFs (Jiang et al. 1996; Palmer et al. 1996), acting as coincidence detectors with a relatively narrow coincidence window (Palmer and Winter 1996); they respond better to broadband signals than to pure tones; and they exhibit relatively wide dynamic ranges (Smith and Rhode 1986; Winter and Palmer 1995). Physiologically characterized, VCN onset cells have been found to exhibit large multipolar morphology (Smith and Rhode 1989), and VCN cells with this morphology have been found to be glycinergic (Doucet et al. 1999) and are thought to provide inhibition of other neurones in the cochlear nucleus such as the T stellate cells (Ferragamo et al. 1998).

\section{Projection to the contralateral DCN}

One of our On-C axons could be traced throughout its entire trajectory to the contralateral DCN, while three of the other On-C cells gave rise to an axon which followed the same course before fading and becoming untraceable in the white matter below the fourth ventricle. A previous study in rat (Friauf and Ostwald 1988) indicated that onset responding cells ("presumably stellate") in the ventral cochlear nu- cleus projected to various superior olive and periolivary sites as well as to the contralateral lateral lemniscus. We found no evidence of such ramifications, even in the axon that was traced to the contralateral cochlear nucleus. Indeed, the projection of the onset cells of Friauf and Ostwald is reminiscent of those of octopus cells described by Adams (1979). Octopus cells have been reported to show onset-type responses (Godfrey et al. 1975; Rhode et al. 1983) and to project to the ventral nucleus of the lateral lemniscus (Schofield and Cant 1997).

A commissural projection from one cochlear nucleus to the other has been shown previously (Shore et al. 1992). This involved large multipolar cells of the VCN that appeared to contact fusiform cells and other cell types in the fusiform and deep cell layers (Schofield and Cant 1996). Earlier physiological evidence also suggested an inhibitory pathway between the two cochlear nuclei (Mast 1970) and there is good evidence that it is glycinergic (Wenthold 1987; Wenthold et al. 1987). In the cat it has been proposed that On-C cells provide a wideband inhibition of projection neurones in the contralateral DCN (Joris and Smith 1998). More recently, an in vivo study has provided convincing evidence that On-C cells provide a monosynaptic inhibition of $\mathrm{T}$ stellate chopper cells in the contralateral and ipsilateral VCN (Needham and Paolini 2003). Stimulation of the cochlear nucleus in an isolated brain preparation evoked short latency (3$9 \mathrm{~ms}$ ) inhibition consistent with mono- and disynaptic connections in all major cell types in the contralateral cochlear nucleus (Babalian et al. 1999). Our demonstration of an On-C commisural connection would be consistent with these inhibitory functions.

It is possible that On-C cells may enhance the firing rate of some contralateral projection neurones by contacting local inhibitory neurones and producing disinhibition (Alibardi 2000).

Careful examination of our On-L-containing sections yielded no evidence for a projection beyond the ipsilateral nucleus in these cells. In our sample population, there was a clear distinction between On-C cells-which had a contralateral projection-and OnL cells which did not. Antidromic stimulation of VCN in the rat also indicated that only a proportion of onset cells projected across the midline while others did not (Needham and Paolini 2003). However, at present it is still not possible to exclude the possibility that some On-L cells may also project across the midline to the other cochlear nucleus.

Either way, it seems likely the On-C cells are involved in the first binaural interaction underlying absolute sound localization of elevation and azimuth using spectral cues. They are apparently not involved in the azimuthal discrimination between two sound sources as this has a different mechanism (May 2000). 


\section{ACKNOWLEDGMENTS}

We are grateful to Didier Pinault, University of Strasbourg, for his helpful comments and advice during the initial implementation of the juxtacellular technique.

\section{REFERENCES}

Adams JC. Ascending projections to the inferior colliculus. J. Comp. Neurol. 183:519-538, 1979.

AlibARDi L. Ultrastructural and immunocytochemical characterisation of commissural neurons in the ventral cochlear nucleus of the rat. Anat. Anz. 180:427-438, 1998.

Alibardi L. Cytology, synaptology and immunocytochemistry of commisural neurons and their putative axonal terminals in the dorsal cochlear nucleus of the rat. Anat. Anz. 182:207-220, 2000.

AlibARDi L. Fine structure and neurotransmitter cytochemistry of neurons in the rat ventral cochlear nucleus projecting to the ipsilateral dorsal cochlear cochlear nucleus. Anat. Anz. 183:459469, 2001.

Babalian AL, Ryugo DK, Vischer MW, Rouiller EM. Inhibitory synaptic interactions between cochlear nuclei: evidence from an in vitro whole brain study. Neuroreport 10:1913-1917, 1999.

Blackburn CC, SACHS MB. Classification of unit types in the anteroventral cochlear nucleus: PST histograms and regularity analysis. J. Neurophysiol. 62:1303-1329, 1989.

Brawer JR, Morest DK, Kane EC. The neuronal architecture of the cochlear nucleus of the cat. J. Comp. Neurol. 155:251-300, 1974.

Bullock DC, Palmer SR, Rees A. Compact and easy-to-use tungstenin-glass microelectrode manufacturing workstation. Med. Biol. Eng. Comput. 26:669-672, 1988.

CAnT NB. The fine structure of two types of stellate cells in the anteroventral cochlear nucleus of the cat. Neuroscience 6:2643$2655,1981$.

DAvis KA, Young ED. Pharmacological evidence of inhibitory and disinhibitory neuronal circuits in dorsal cochlear nucleus. J. Neurophysiol. 83:926-940, 2000.

Doucet JR, Ryugo DK. Projections from the ventral cochlear nucleus to the dorsal cochlear nucleus in rats. J. Comp. Neurol. 385:245-264, 1997.

Doucet JR, Ross AT, Gillespie MB, Ryugo DK. Glycine immunoreactivity of multipolar neurons in the ventral cochlear nucleus which project to the dorsal cochlear nucleus. J. Comp. Neurol. 408:515-531, 1999.

Evans EF, Nelson PG. The responses of single neurones in the cochlear nucleus of the cat as a function of their location and anaesthetic state. Exp. Brain Res. 17:402-427, 1973.

Ferragamo MJ, Golding NL, Oertel D. Synaptic inputs to stellate cells in the ventral cochlear nucleus. J. Neurophysiol. 79:51-63, 1998.

FRIAUF E, OsTwald J. Divergent projections of physiologically characterised rat ventral cochlear nucleus neurons as shown by intra-axonal injection of horseradish peroxidase. Exp. Brain Res. 73:263-284, 1988.

Godfrey DA, KIANG NYS, Norris BE. Single unit activity in the posteroventral cochlear nucleus of the cat. J. Comp. Neurol. 162:247-268, 1975.

HaCKNeY CM, PICK GF. The distribution of spherical cells in the anteroventral cochlear nucleus of the guinea pig-some light microscopic observations. Br. J. Audiol. 20:215-220, 1986.

Jiang D, Palmer AR, Winter JM. The frequency extent of two-tone facilitation in onset units in the ventral cochlear nucleus. J. Neurophysiol. 75:380-395, 1996.
JoRIs PX, SMITH PH. Temporal and binaural properties in dorsal cochlear nucleus and its output tract. J. Neurosci. 18:1015710170, 1998.

Mast TE. Binaural interaction and contralateral inhibition in dorsal cochlear nucleus of the chinchilla. J. Neurophysiol. 33:108115,1970

MaY B. Role of the dorsal cochlear nucleus in the sound localisation behavior of cats. Hear. Res. 148:74-87, 2000.

Needham K, Paolini AG. Fast inhibition underlies the transmission of auditory information between cochlear nuclei. J. Neurosci. 23:6357-6361, 2003.

Nelken I, Young ED. Two separate inhibitory mechanisms shape the responses of dorsal cochlear nucleus type IV units to narrowband and wideband stimuli. J. Neurophysiol. 71:2446-2462, 1994.

Oertel D, Wu SH, Garb MW, Dizack C. Morphology and physiology of cells in slice preparations of the posteroventral cochlear nucleus of mice. J. Comp. Neurol. 295:136-154, 1990.

OsEN KK. The intrinsic organization of the cochlear nuclei in the cat. Acta Otolaryngol. 67:352-359, 1969.

Osen KK, OtTersen OP, Stormmathisen J. Colocalization of glycinelike and GABA-like immunoreactivities: A semiquantitative study of individual neurons in the dorsal cochlear nucleus of cat. In: Ottersen OP, Storm-Mathisen J (eds) Glycine Neurotransmission. John Wiley \& Sons Ltd., New York, pp 417-452, 1990.

Ostapoff EM, Morest DK, Parham K. Spatial organisation of the reciprocal connections between the cat dorsal and ventral cochlear nuclei. Hear. Res. 130:75-93, 1999.

Palmer AR, Winter IM. The temporal window of two-tone facilitation in onset units of the ventral cochlear nucleus. Audiol. Neurootol. 1:12-30, 1996.

Palmer AR, Jiang D, Marshall DH. Responses of ventral cochlear nucleus onset and chopper units as a function of signal bandwidth. J. Neurophysiol. 75:780-795, 1996.

Palmer AR, Wallace MN, Arnott RH, Shackleton TM. Morphology of physiologically characterised ventral cochlear nucleus stellate cells. Exp. Brain Res. 153:418-426, 2003.

PFeIfFER RR. Classification of response patterns of spike discharges for units in the cochlear nucleus: Tone burst stimulation. Exp. Brain Res. 1:220-235, 1966.

Pinault D. A novel single-cell staining procedure performed in vivo under electrophysiological control: morpho-functional features of juxtacellularly labelled thalamic cells and other central neurons with biocytin or neurobiotin. J. Neurosci. Meth. 65:113-136, 1996.

Pressnitzer D, Meddis R, Delahaye R, Winter IM. Physiological correlates of comodulation masking release in the mammalian ventral cochlear nucleus. J. Neurosci. 21:6377-6386, 2001.

RAPISARDA C, BACCHElli B. The brain of the guinea pig in stereotaxic coordinates. Arch. Sci. Biol. 61:1-37, 1977.

RHode WS. Vertical cell responses to sound in cat dorsal cochlear nucleus. J. Neurophysiol. 82:1019-1032, 1999.

Rhode WS, Greenberg S. Encoding of amplitude modulation in the cochlear nucleus of the cat. J. Neurophysiol. 71:1797-1825, 1994a.

Rhode WS, Greenberg S. Lateral suppression and inhibition in the cochlear nucleus of the cat. J. Neurophysiol. 71:493-514, 1994b.

Rhode WS, Oertel D, Smith PH. Physiological response properties of cells labelled intracellularly with horseradish peroxidase in cat ventral cochlear nucleus. J. Comp. Neurol. 213:448-463, 1983.

Rose JE, Galambos R, Hughes JR. Microelectrode studies of the cochlear nucleus of the cat. Bull. Johns Hopkins Hospital 104:211-251, 1959

Ryugo DK, Willard FH. The dorsal cochlear nucleus of the mouse: a light microscopic analysis of neurons that project to the inferior colliculus. J. Comp. Neurol. 242:381-396, 1985. 
SCHOFIELd BR, CANT NB. Origins and targets of commissural connections between the cochlear nuclei in guinea pigs. J. Comp. Neurol. 375:128-146, 1996.

SCHOFIELD BR, CANT NB. Ventral nucleus of the lateral lemniscus in guinea pigs: Cytoarchitecture and inputs from the cochlear nucleus. J. Comp. Neurol. 379:363-385, 1997.

Shofner WP, Young ED. Excitatory/inhibitory response types in the cochlear nucleus: Relationships to discharge patterns and responses to electrical stimulation of the auditory nerve. J. Neurophysiol. 54:917-939, 1985.

Shore SE, Godfrey DA, Helfert RH, Altschuler RA, Bledsoe SC. Connections between the cochlear nuclei in guinea pig. Hear. Res. 62:16-26, 1992.

Smith PH, Rhode WS. Encoding timing and intensity in the ventral cochlear nucleus of the cat. J. Neurophysiol. 56:261-286, 1986.

Sмith PH, Rhode WS. Structural and functional properties distinguish two types of multipolar cells in the ventral cochlear nucleus. J. Comp. Neurol. 282:595-616, 1989.

Spirou GA, MAy BJ, Wright DD, Ryugo DK. Frequency organization of the dorsal cochlear nucleus in cats. J. Comp. Neurol. 329:3652, 1993.

Stabler SE. The neural representation of simple and complex sounds in the dorsal cochlear nucleus of the guinea pig. Thesis, University of Nottingham, UK, 1991.

WENTHOLD RJ. Evidence for a glycinergic pathway connecting the 2 cochlear nuclei-an immunocytochemical and retrograde transport study. Brain Res. 415:183-187, 1987.
Wenthold RJ, Huie D, Altschuler RA, Reeks KA. Glycine immunoreactivity localized in the cochlear nucleus and superior olivary complex. Neuroscience 22:897-912, 1987.

Winter IM, Palmer AR. Responses of single units in the anteroventral cochlear nucleus of the guinea pig. Hear. Res. 44:161178, 1990.

Winter IM, Palmer AR. Level dependency of cochlear nucleus onset unit responses and facilitation by second tones or broadband noise. J. Neurophysiol. 73:141-159, 1995.

Young ED. Response characteristics of neurones of the cochlear nuclei. In: Berlin C (ed) Hearing Sciences. College-Hill Press, San Diego, pp 423-460, 1984.

Young ED, BRownell WE. Responses to tones and noise of single cells in dorsal cochlear nucleus of unanesthetized cats. J. Neurophysiol. 39:282-300, 1976.

Young ED, DAvIs KA. Circuitry and functions of the dorsal cochlear nucleus. In: Oertel D, Popper AN, Fay RR (eds) Integrative functions of the mammalian auditory pathway. Springer-Verlag, New York, pp 160-206, 2002.

Young ED, Robert J-M, SHOFNER WP. Regularity and latency of units in ventral cochlear nucleus: Implications for unit classification and generation of response properties. J. Neurophysiol. 60:129, 1988.

Young ED, Voigt HF. Response properties of type II and type III units in dorsal cochlear nucleus. Hear. Res. 6:153-169, 1982.

Kiang NYS, Watanabe T, Clarke EC, Clark LF. Discharge patterns of single fibers in the cat's auditory nerve. M.I.T., Cambridge, Mass, 1950. 